Elsevier required licence: (C) <2018>. This manuscript version is made available under the CC-BY-NC-ND 4.0 license http://creativecommons.org/licenses/by-nc-nd/4.0/ 


\title{
A novel shift control concept for multi-speed electric vehicles
}

Wenwei $\mathrm{Mo}^{1}$, Paul D. Walker ${ }^{1 *}$, Yuhong Fang ${ }^{1}$, Jinglai $\mathrm{Wu}^{1}$, Jiageng Ruan ${ }^{1}$, and Nong Zhang ${ }^{1}$

1. School of Mechanical and Mechatronic Systems; University of Technology Sydney; 15 Broadway, Ultimo, NSW, Australia, 2007

\begin{abstract}
This paper proposes a novel synchronizer 'Harpoon-Shift' aiming at improving the comfort and efficiency of gearbox, meanwhile, simplifying the shifting control strategy for multi-speed electric vehicles. It will overcome one of the biggest shortcomings of traditional synchronizer system with frictional cone clutch.
\end{abstract}

Experiment is established to investigate the torque and speed responses during the engagement of gears pairs. Then, based on previous testing results, the relationship of the peak torque and minimum speed difference to implement gear shifting with various spring coefficients is investigated. In addition, a mathematical model of the Harpoon-Shift system is developed to simulate the engagement process. The simulation results of system transient responses are validated against the data measured on testing rig. The model is then improved to study the impact of the rotating inertia, speed and speed difference on the torsional vibration and required time of engagement. Both of the simulation and experimental results show the significant improvement of proposed synchronizer to conventional cone clutch synchronizer.

Keywords: Harpoon-shift; Synchronizer; Electric vehicle; Shift control; Engagement dynamics; Torsional vibration.

\section{Introduction}

The application of multi-speed transmissions in electric vehicles (EVs) continues to grow as a result of improved performance and driving efficiency in comparison to single speed EVs [1]. Traditionally, shifting and gear selection is performed with the use of friction clutches, a result of both limited controllability and high inertia of combustion engines. These friction elements are a major source of inefficiency in multi-speed gearboxes [2-4]. As electric motors are significantly more controllable that their conventional counterparts, as evidenced by paper such as [5-7], reliance on inefficient friction elements can be reduced, and even eliminated. This has resulted in the development of shift control strategies that rely on motor control rather than friction based strategies [8-10]. However, as shown in [11] these strategies cannot entirely eliminate the need for torsional vibration absorption during clutch lockup.

As established by a number of comprehensive studies on integral control of multi-speed electric vehicle (MSEV) platforms [6,12-14], and in particular those with clutchless automated manual transmissions (CLAMT) [6,12,15-16], the need for friction clutches for speed synchronisation in EV shift control is reducing. Whilst these are still necessary for AT [13] and DCT [14] based platforms, CLAMTs can, in theory, achieve functional control without the use of friction clutches [5,7]. 
To minimize losses, the design of synchronization mechanisms is critical in applications substantially affected by system efficiency, i.e. electric vehicles [17]. Energy in an open synchroniser clutch is consumed as viscous drag. In papers such as [2,3] it is demonstrated to have a significant impact on powertrain operating efficiency. This is undesirable for multi-speed electric vehicle platforms that need to minimise any power losses [18]. The use of dog clutches alone, however, has limitations with "clash" type failures that occur when there is a high relative speed during engagement $[4,19,20]$. In [11], a controllable one-way-clutch was developed to free the use of friction elements. However, it demonstrated that substantial transients resulted from engagement as a friction clutch was used to absorb any transient shock.

This paper presents a novel gear engagement mechanism, which only consists of a torsional shock absorber and a dog clutch. It is designed to overcome any speed difference within the engaging gear set and to minimize transients during the gear shift process. Ultimately, it provides a means to select and engage gears without the use of friction clutches. The prototype demonstrated in this research offers a unique technique for overcoming issues arising from high relative speeds during engagement. This mechanism relies on relative speed difference between sleeve hub and target gear and must ensure the hub is faster than the target gear to achieve engagement. Fig. 1 presents a cross-section view of the proposed novel synchronizer in this study. It consists of input and output shafts (No. 8 and 1), sleeve (No. 6) and sleeve hub (No. 7), and guide ring (No. 2) and springs (No. 9) as the main components for actuation. As detailed extensively in the remained of this paper, this actuator relies on the use of the primary traction motor to synchronise its speed toward designed threshold. It use the integral torsion springs to absorb residual relative motion followed by locking the target shaft to the transmission, engaging the desired gear and allowing the delivery of traction load to the wheel.

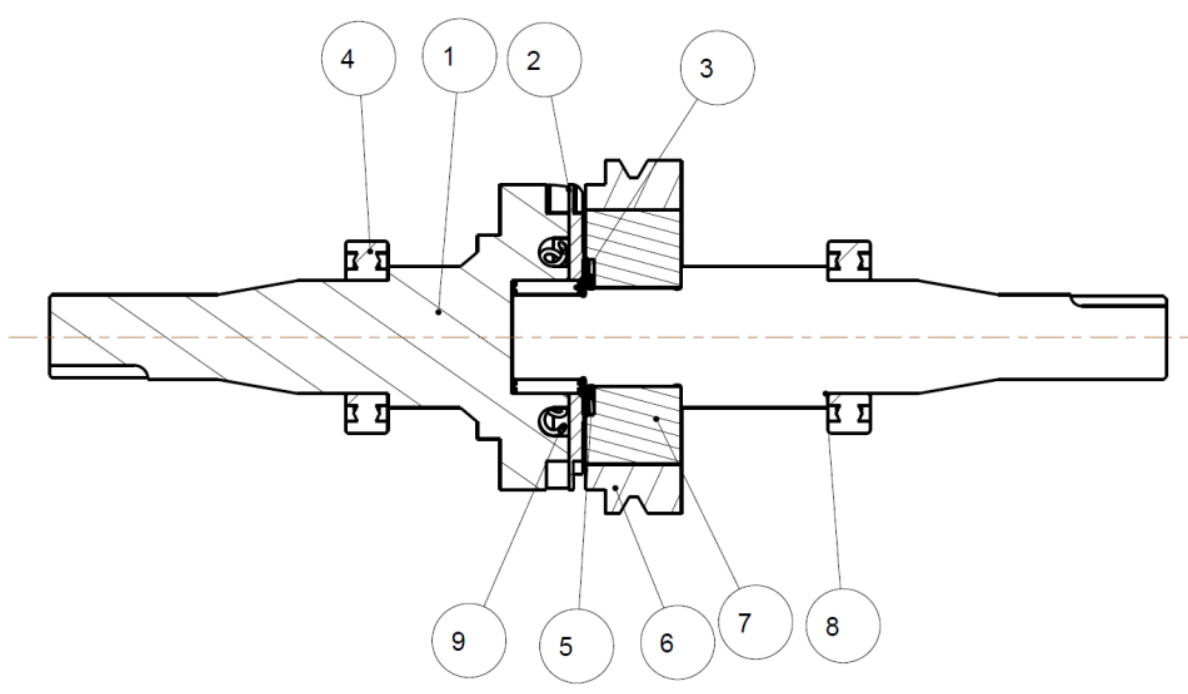

Fig. 1. Section view of 'Harpoon' shift gear engagement mechanism: (1) output shaft, (2) guide ring, (3) needle bearing, (4) deep groove ball bearings, (5) retaining ring, (6) sleeve, (7) sleeve hub, (8) input shaft, and (9) springs.

In summary, this study proposes a novel actuation device for the gears engagement in multi-speed EVs. The remainder of this paper is divided into (ii) details of the proposed synchronizer, gear shift control, (iii) mathematical model of engagement (iv) simulation results, and analysis of rotating inertia, speed and speed difference on torsional vibration, (v) rig setup, variables analyzing, and experimental results, and finally, (vi) conclusions drawn from these results. 


\section{Prototype Concept}

In MSEV platforms where speed control of the traction motor is possible for gear synchronizing, the gear engagement process could be significantly simplified. A conventional synchroniser mechanism requires (i) matching speed between a freewheeling gear and shaft by using a cone clutch, (ii) physically interlocking the gear to the shaft by using a dog clutch, and (iii) seeking no premature engagement leading to the damage of mechanical parts via the design of dog and cone clutches $[4,19]$. Through the application of electrical speed synchronization in MSEVs, the engagement process can be simplified. For this type of transmission, the mechanism must (i) absorb any residual relative motion between gear and shaft and (ii) physically interlock the system.

According to these requirements, a new concept synchronization mechanism is proposed. It incorporates a synchroniser groove and a sleeve to lock the gear and shaft after speed matching, and a guiding component capable to match gear and shaft speed. The speed synchronization between gear and its respective shaft is implemented by radial flexible components. The interlocking of the mechanism is implemented by angled chamfers on the synchroniser groove and the sleeve, or the locking of the shifting actuator. Fig. 2 presents the assembling drawing of the Harpoon-shift concept, comprising of constant mesh gear, dog gear, torque springs, sleeve, hub and shaft.

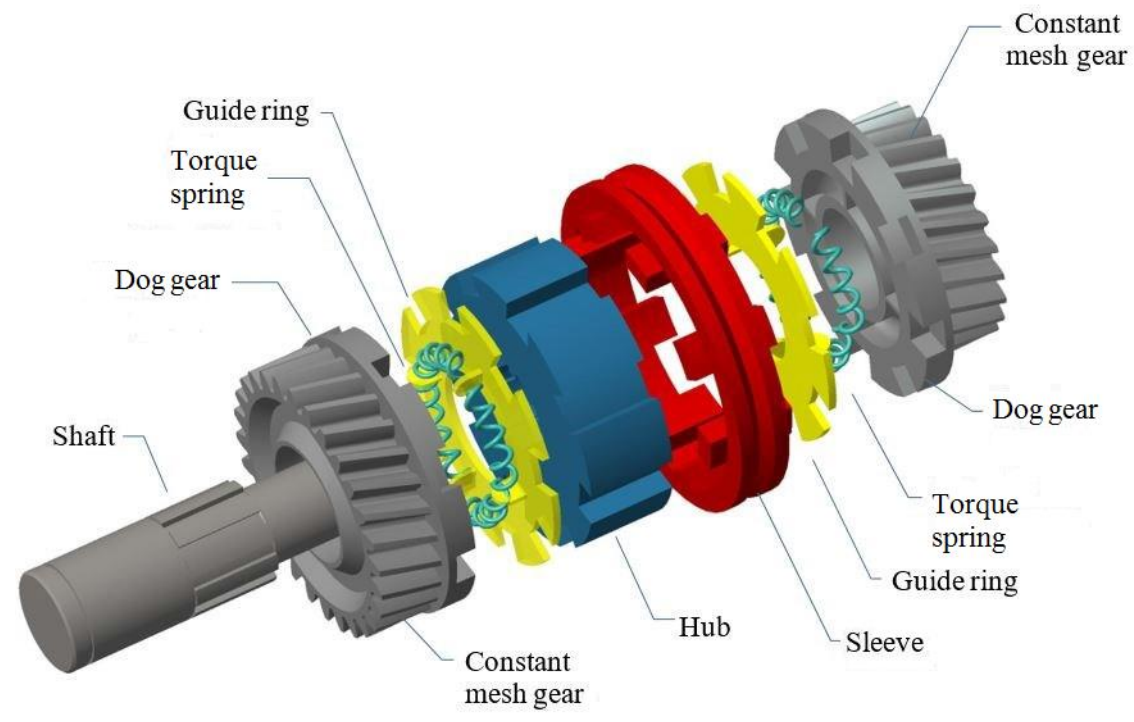

Fig. 2. Exploded view of the Harpoon-Shift concept.

The functions of the main components for the Harpoon Shift mechanism are as follows:

- Constant mesh gear: these are common gears in lay-shaft type transmissions. Typically, the gears are supported on the primary shaft with a needle bearing to allow relative rotation when freewheeling and secured against axial movement to the shaft.

- Dog gear: matches the speed of the gear with the speed of the Harpoon-shift hub and output shaft. The external groove interlocks with the internal prong of the Harpoon-shift sleeve. Internal circular grooves retain the torque springs.

- Torque spring: one end contacting with the step of the dog gear and the other side remains in contact with the guide ring. Typically, the guide ring compresses the spring, providing a torque to counteract residual relative speed between the hub and constant mesh gear before the sleeve completes engagement. 
- Guide ring: this ring has chamfers on one side to guide the sleeve to insert the synchroniser groove smoothly. Once the sleeve has mated with the guide ring, relative motion between sleeve and dog gear will compress the spring. To do so, tabs on the other side for ring engage the torque spring.

- Harpoon-shift sleeve: this could be engaged by using an actuator via the gearshift fork. It has internal splines that are in constant mesh with the Harpoon-shift hub external splines, so it can only move axially from the neutral position to an engaged position. The main function of the prongs is to engage with the guide ring during speed matching and interlock with the dog gear when engaged.

- Harpoon-shift hub: is mounted on the rotating shaft via a spline.

- Shaft: It has an external spline that constantly mesh with the internal splines of the Harpoonshift hub and supports the idle constant mesh gears through bearings.

Compared with the conventional synchronizer, the advantages of the new mechanism are as follows:

(i) No friction elements for speed synchronisation. This can reduce power losses during gear shifting.

(ii) Requiring only a small thrust load for engagement. The actuation force can be supplied by a small motor rather than by a heavy and complicated hydraulic system. This is desirable for electric vehicles.

(iii) Simpler actuation process. Harpoon-shift relies on mechanical system (i.e. limiting mechanism) to control the axial motion of sleeve during engagement. Thus it could use open loop control instead of closed loop control to accomplish engagement.

(iv) Fewer components than traditional synchronisers. This can improve the reliability and extend the service life of synchronisation mechanism.

The limitation of this design, however, is the need to use an electric drive to complete the synchronisation process. Such actuation methodologies are suggested in a number of research articles focused on AMTs for electric vehicle applications [6,7,10]. For a traditional synchroniser, there is a requirement of using relatively high force based (typically $500 \sim 1000 \mathrm{~N}$ ) actuators to both engage the frictional cone clutch and perform ring unblocking and indexing in the dog gear $[3,4,19,20]$. The proposed design overcomes these issues, and instead relies on kinetic energy in the relative motion between engaging gear and shaft to perform these guide ring realignment duties. Thus, the control process is simplified and actuation load is significantly lowered. In testing discussed in Section 5.1, a peak load of $47 \mathrm{~N}$ is required for actuation of the sleeve. The simplified control process is stated as follows:

1. De-energise prime mover (i.e. electric motor).

2. Release engaged gear.

3. Use prime mover to synchronise input shaft to a speed greater than the target gear.

4. Engage the Harpoon-shift actuator according to Section 3.

5. Re-instate drive load.

The key operating principle for this mechanism is to apply the stored kinetic energy in the target gear's reflected inertia to compress the torque spring and rotate the guide ring into an open position enabling engagement of the dog clutch on the sleeve. For example, if the spring stiffness is too high, there will 
not be sufficient energy stored in the system to realign the guide ring and complete engagement. In contrast, if the stiffness is too low, the insufficient absorbed energy will result in undesirable transients in the powertrain. The spring stiffness can be designed with reasonable accuracy to ensure successful engagements over a range of differential speeds.

For a torsional spring the stored energy is:

$$
E_{S}=\frac{1}{2} K_{S} \theta^{2}
$$

where $E_{S}$ is the spring energy, $K_{S}$ is the spring stiffness and $\theta$ is the angular rotation. The kinetic energy stored in the rotating elements of the powertrain upstream of the mechanism is:

$$
E_{K}=\frac{1}{2} J_{G}\left(\omega_{G}^{2}-\omega_{S}^{2}\right)
$$

where $E_{K}$ is the kinetic energy, $J_{G}$ is the inertia of the powertrain upstream of the target gear, $\omega_{G}$ is the rotational speed of the gear, $\omega_{S}$ is the rotational speed of its respective shaft. Noting particularly here that the spring is required to absorb only the energy needed to reduce the gear speed to the target speed through a particular compression of the spring. Then it is possible to arrive at a solution for the spring stiffness as follows:

$$
K_{S}=\frac{J_{G}\left(\omega_{G}^{2}-\omega_{S}^{2}\right)}{\theta^{2}}
$$

This simple calculation allows for the design of a range of functional speeds where the mechanism will successfully engage. However, it is the ideal load and does not account for energy consumed by losses in the system. Such issues will increase the minimum speed required for engagement. Therefore the two main issues requiring investigation are (1) variation of the spring stiffness and its impact on engagement, and (2) determination of minimum differential speed for a given spring stiffness.

\section{Actuation process and modeling}

The model of Harpoon-shift prototype used in the test (see Section 5.1) is shown in Fig. 3. Since two mechanical couplings are used in the test to absorb the torsional oscillation, two linear spring dampers $\left(k_{1} \& c_{1}, k_{2} \& c_{2}\right)$ are applied in the model to represent the elasticity and damping of the rubber inserts of the couplings. Additionally, the clearance between the insert and mechanical components is not taken into consideration in the study.

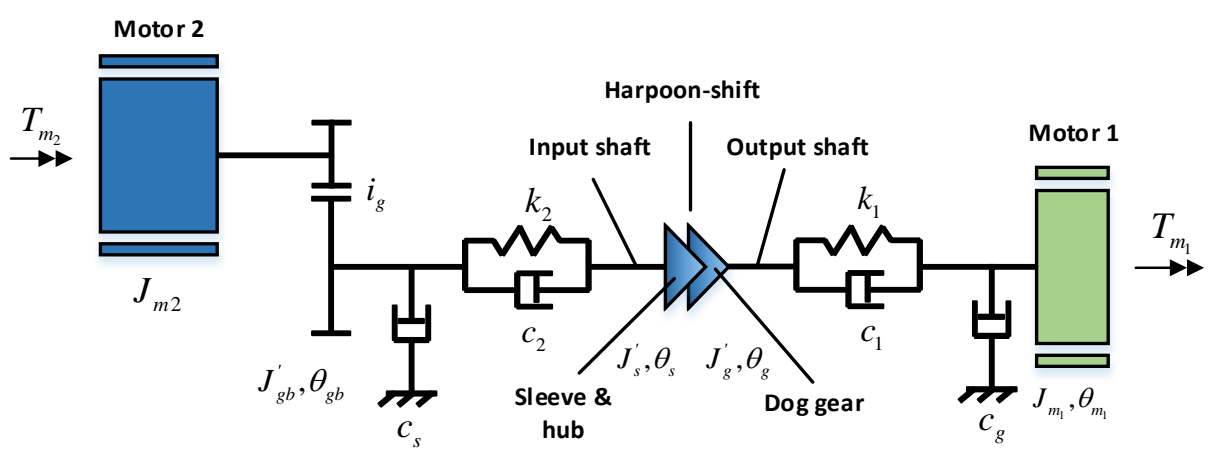

Fig. 3. The model of the Harpoon-shift prototype. 
For a clear demonstration of the working process, the Harpoon-shift is simplified to four main important components, i.e. two external grooves of the dog gear, two guide blocks of the guide ring, two prongs of the Harpoon-shift sleeve as shown in the sketch of Fig. 4 and torque springs which are not shown due to the fact that they are installed inside the assembly [21].

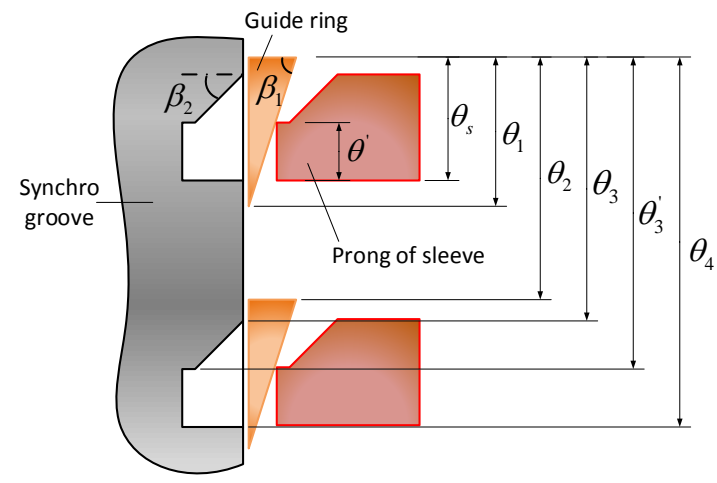

Fig. 4. Working components and angular parameters of Harpoon-shift.

The engagement of the Harpoon-shift has several stages as the guide ring is engaged and the sleeve slides forward along the shaft, rotating and compressing springs to match speed of shaft and idle gear before completing gear engagement. In practice, the alignment at the start of engagement could be different, because the time at which a shift occurs in the driving of vehicle is random. As a result, the relative position between the holes of the guide ring and the prongs of the sleeve is random at this stage of the engagement process. The whole working process can be divided into seven stages according to the displacement of the sleeve and the angle of rotation. The start and end of each phase are detailed below:

Stage $1\left(0 \leq \theta_{s}<\theta^{\prime} \& x_{s} \leq x_{t}\right)$ :

The first stage is illustrated in Fig. 5. This phase starts with the Harpoon-shift sleeve at the neutral position. At the beginning of this phase, the gear to be engaged is determined. The shift fork begins to push the sleeve forward to the selected constant mesh gear. There is a speed difference between the sleeve and the dog gear during this phase, and the relative position between the prongs and the block of the guide ring decides the number of phases during the process of the engagement. In this research, the actuation force, $F_{a}$, is supplied by a pneumatic cylinder. If the prong touches the front face of the guide ring, its axial movement is blocked immediately. Otherwise, it moves axially until it contacts the chamfer of the guide ring or the flat head face of the dog gear, which indicates that the engagement process enters the stage 2 or 3 .

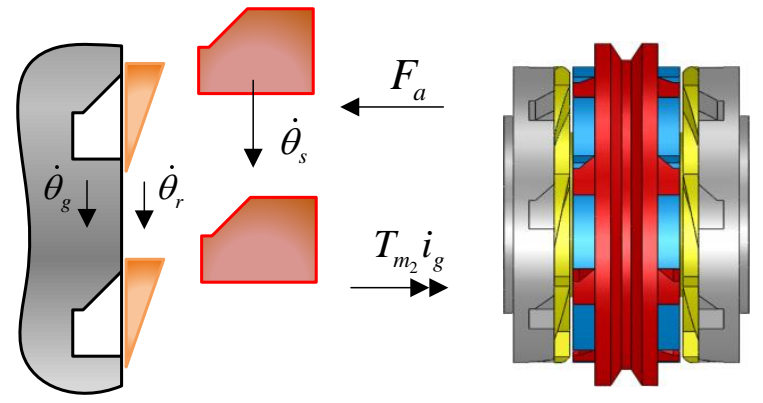

Fig. 5. The position of the Harpoon-shift components during the first stage.

The equations of motions referring to this stage are expressed as follows: 


$$
\begin{aligned}
& J_{s}^{\prime} \ddot{\theta}_{s}=-k_{2}\left(\theta_{s}-\theta_{g b}\right)-c_{2}\left(\dot{\theta}_{s}-\dot{\theta}_{g b}\right) \\
& J_{e q}^{\prime} \ddot{\theta}_{g b}=T_{m_{2}} i_{g}-c_{s} \dot{\theta}_{g b}+k_{2}\left(\theta_{s}-\theta_{g b}\right)+c_{2}\left(\dot{\theta}_{s}-\dot{\theta}_{g b}\right) \\
& J_{g}^{\prime} \ddot{\theta}_{g}=k_{r g}\left(\theta_{r}-\theta_{g}\right)+c_{r g}\left(\dot{\theta}_{r}-\dot{\theta}_{g}\right)-k_{1}\left(\theta_{g}-\theta_{m_{1}}\right)-c_{1}\left(\dot{\theta}_{g}-\dot{\theta}_{m_{1}}\right) \\
& J_{m_{1}}^{\prime} \ddot{\theta}_{m_{1}}=-T_{m_{1}}-c_{g} \dot{\theta}_{m_{1}}+k_{1}\left(\theta_{g}-\theta_{m_{1}}\right)+c_{1}\left(\dot{\theta}_{g}-\dot{\theta}_{m_{1}}\right) \\
& J_{r} \ddot{\theta}_{r}=-k_{r g}\left(\theta_{r}-\theta_{g}\right)-c_{r g}\left(\dot{\theta}_{r}-\dot{\theta}_{g}\right) \\
& m_{s} \ddot{x}_{s}=F_{a}-F_{L t 1}
\end{aligned}
$$

where

$$
F_{a}=A_{c} P_{c}-c_{x} \dot{x}_{s}
$$

$k_{i}(i=1,2)$ are equivalent stiffness coefficients, and $c_{i}(i=1,2, s, g)$ are damping coefficients. $k_{r g}$ is the equivalent stiffness coefficient of the integral torque springs. Here $k_{r g}=n_{s} k_{s 1} R_{s}^{2}$, where $n_{s}$ is the number of the springs, $k_{s 1}$ is the linear stiffness coefficient of the springs (see Table 3 ), $R_{s}$ is the mean distribution radius of torsion springs. $c_{r g}$ is the equivalent damping coefficient. $J_{s}^{\prime}$ is an equivalent inertia, which includes the inertias of the sleeve, hub and coupling, $J_{e q}^{\prime}$ is an equivalent inertia, $J_{e q}^{\prime}=J_{g b}^{\prime}+i_{g}^{2} J_{m_{2}}$, where $J_{g b}^{\prime}$ represents the equivalent inertia of gearbox on the output shaft, $i_{g}$ is the gearbox ratio, $J_{m_{2}}$ is the inertia of motor 2. $J_{g}^{\prime}$ is the sum of the inertia of dog gear and coupling. $J_{m_{1}}^{\prime}$ is an inertia taking into account the inertias of the motor 1 and coupling. $J_{r}$ is the inertia of guide ring. $m_{s}$ is the sleeve mass. The angular displacement, velocity and acceleration of sleeve, gearbox output shaft, dog gear, motor 1 and guide ring are represented as $\theta_{s}, \theta_{g b}, \theta_{g}, \theta_{m_{1}}$ and $\theta_{r}$ and corresponding time derivatives, while $x_{s}$ represents the axial displacement of the sleeve. $T_{m_{1}}$ is the torque of the motor 1 used as resistance torque, and $T_{m_{2}}$ is the torque applied to keep the motor 2 rotating at a constant speed. $A_{c}$ is the sectional area of the cylinder piston, $P_{c}$ is the air pressure in the cylinder chamber, $c_{x}$ is the viscous friction coefficient. $F_{L t 1}$ is the force acting on the sleeve prongs from limiting mechanism (the guide ring front face), which is shown in Appendix A in detail.

The differential equation for $P_{c}$ in Eq. 10 is given by [22, 23]

$$
\dot{P}_{c}=\frac{\beta_{c}}{V_{o}+A_{c} x_{s}}\left(Q_{c}-A_{c} \dot{x}_{s}\right)
$$

where $V_{o}$ is the chamber minimum volume at $x_{s}=0, \beta_{c}$ is the bulk modulus of the air, and $Q_{c}$ is the air flow computed by

$$
Q_{c}=\operatorname{sgn}\left(P_{i n}-P_{c}\right) C_{d} A_{o} \sqrt{\frac{2\left|P_{i n}-P_{c}\right|}{\rho_{\text {air }}}}
$$


where $C_{d}$ is the discharge coefficient, $P_{i n}$ is the supply pressure directly provided by an air pump, $\rho_{\text {air }}$ is the air density, $A_{o}$ is the orifice area.

Stage $2\left(\theta^{\prime} \leq \theta_{s}<\theta_{1}+\theta^{\prime}\right)$ :

The second stage is shown in Fig. 6. This phase starts with the contact between the prong of the Harpoon-shift sleeve and the chamfer of the guide ring. Under the pressure of the shift fork, the prong of the sleeve continues sliding on the chamfer of the guide ring, and the friction on the surface starts to increase. During the phase, the guide ring blocks the grooves of the dog gear, which thus prevents premature locking. The phase ends with separation between the chamfer block of the guide ring and the prong of the sleeve and the contact between the flat head face of the dog gear and the prong.

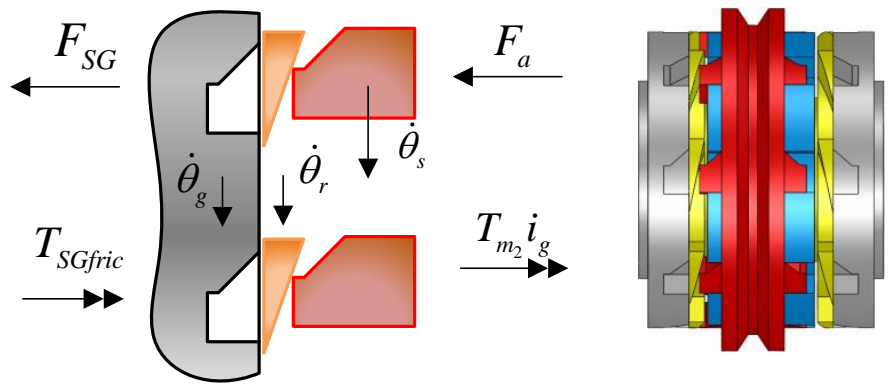

Fig. 6. The position of the Harpoon-shift components during the second stage.

The equations of motions regarding this stage of the process are the following:

$$
\begin{aligned}
& J_{s}^{\prime} \ddot{\theta}_{s}=F_{a} R_{m} \frac{1-\mu_{s} \tan \beta_{1}}{\tan \beta_{1}+\mu_{s}}-k_{2}\left(\theta_{s}-\theta_{g b}\right)-c_{2}\left(\dot{\theta}_{s}-\dot{\theta}_{g b}\right) \\
& J_{e q}^{\prime} \ddot{\theta}_{g b}=T_{m_{2}} i_{g}-c_{s} \dot{\theta}_{g b}+k_{2}\left(\theta_{s}-\theta_{g b}\right)+c_{2}\left(\dot{\theta}_{s}-\dot{\theta}_{g b}\right) \\
& J_{g}^{\prime} \ddot{\theta}_{g}=k_{r g}\left(\theta_{r}-\theta_{g}\right)+c_{r g}\left(\dot{\theta}_{r}-\dot{\theta}_{g}\right)-k_{1}\left(\theta_{g}-\theta_{m_{1}}\right)-c_{1}\left(\dot{\theta}_{g}-\dot{\theta}_{m_{1}}\right) \\
& J_{m_{1}}^{\prime} \ddot{\theta}_{m_{1}}=-T_{m_{1}}-c_{g} \dot{\theta}_{m_{1}}+k_{1}\left(\theta_{g}-\theta_{m_{1}}\right)+c_{1}\left(\dot{\theta}_{g}-\dot{\theta}_{m_{1}}\right) \\
& J_{r} \ddot{\theta}_{r}=-F_{a} R_{m} \frac{1-\mu_{s} \tan \beta_{1}}{\tan \beta_{1}+\mu_{s}}-k_{r g}\left(\theta_{r}-\theta_{g}\right)-c_{r g}\left(\dot{\theta}_{r}-\dot{\theta}_{g}\right) \\
& m_{s} \ddot{x}_{s}=F_{a}-F_{a}^{\prime}
\end{aligned}
$$

where $R_{m}$ is the mean contact radius between the guide block and sleeve prongs. $\beta_{1}$ is chamfer angle of the guide block. $\mu_{s}$ is the chamfer friction coefficient. $F_{a}^{\prime}$ axial component of the normal force when the sleeve prong contacts the chamfer surface of the guide ring, which is shown in Appendix A in detail. There is a constraint equation between the axial and tangential velocities as they connect on the chamfers [20], i.e. $\dot{x}_{s}=\left(\dot{\theta}_{s}-\dot{\theta}_{r}\right) R_{\text {out }} \cot \beta_{1}$, where $R_{\text {out }}$ is the outside radius of the dog gear. Detailed chamfer friction calculation in Eq. 13 is shown in Appendix B.

Stage $3\left(\theta_{1}+\theta^{\prime} \leq \theta_{s}<\theta_{2}\right)$ : 
The third stage represented in Fig.7. The stage starts with the contact between the flat head face of the synchronizer groove and the prong of the Harpoon-shift sleeve. After slipping down from guide ring, the sleeve prong slides on the flat top of the groove ring under the pressure of the shift fork. The friction between the dog gear and sleeve prongs starts to increase. During this phase, the axial velocity of sleeve is zero (i.e. $\dot{x}_{s}=0$ ). The phase ends with the contact between the flank of the sleeve prong and the flat flank of the next prong of the guide ring.
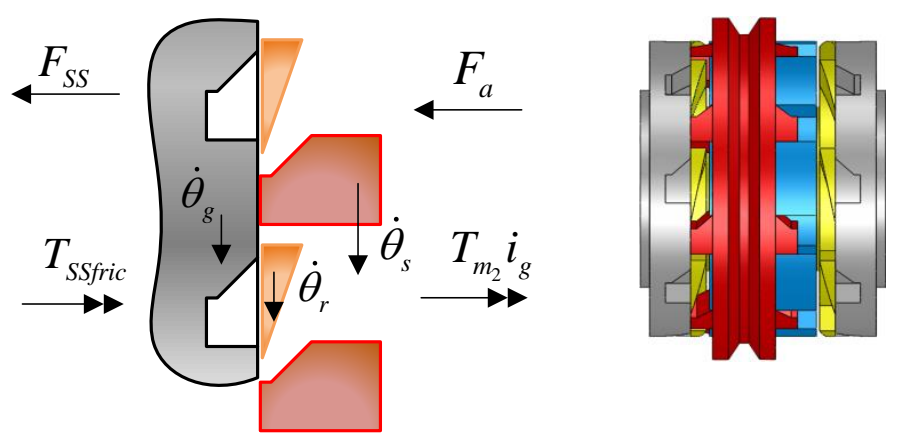

Fig. 7. The position of the Harpoon-shift components during the third stage.

Thus, the equations referring to this phase are:

$$
\begin{aligned}
& J_{s}^{\prime} \ddot{\theta}_{s}=-\mu_{s g} F_{a} R_{m}-k_{2}\left(\theta_{s}-\theta_{g b}\right)-c_{2}\left(\dot{\theta}_{s}-\dot{\theta}_{g b}\right) \\
& J_{e q}^{\prime} \ddot{\theta}_{g b}=T_{m_{2}} i_{g}-c_{s} \dot{\theta}_{g b}+k_{2}\left(\theta_{s}-\theta_{g b}\right)+c_{2}\left(\dot{\theta}_{s}-\dot{\theta}_{g b}\right) \\
& J_{g}^{\prime} \ddot{\theta}_{g}=\mu_{s g} F_{a} R_{m}+k_{r g}\left(\theta_{r}-\theta_{g}\right)+c_{r g}\left(\dot{\theta}_{r}-\dot{\theta}_{g}\right)-k_{1}\left(\theta_{g}-\theta_{m_{1}}\right)-c_{1}\left(\dot{\theta}_{g}-\dot{\theta}_{m_{1}}\right) \\
& J_{m_{1}}^{\prime} \ddot{\theta}_{m_{1}}=-T_{m_{1}}-c_{g} \dot{\theta}_{m_{1}}+k_{1}\left(\theta_{g}-\theta_{m_{1}}\right)+c_{1}\left(\dot{\theta}_{g}-\dot{\theta}_{m_{1}}\right) \\
& J_{r} \ddot{\theta}_{r}=-k_{r g}\left(\theta_{r}-\theta_{g}\right)-c_{r g}\left(\dot{\theta}_{r}-\dot{\theta}_{g}\right) \\
& m_{s} \ddot{x}_{s}=0
\end{aligned}
$$

where $\mu_{s g}$ is the dynamic friction coefficient.

Stage $4\left(\theta_{2} \leq \theta_{s}<\theta_{3}+\theta^{\prime}\right)$ :

The fourth stage is illustrated in Fig. 8. The stage starts from the flank of the sleeve prong contacting the flat flank of the next prong of the guide ring. Then the sleeve begins to push the guide ring to rotate relative to the constant mesh gear and dog gear. Simultaneously, the flexible components (torque springs) between the dog gear and the guide ring are compressed in the internal groove due to the relative angular displacement. Under the transmission of the drive torque through the flexible components, the dog gear and the target gear start to synchronize speeds and align sleeve and the shaft. 


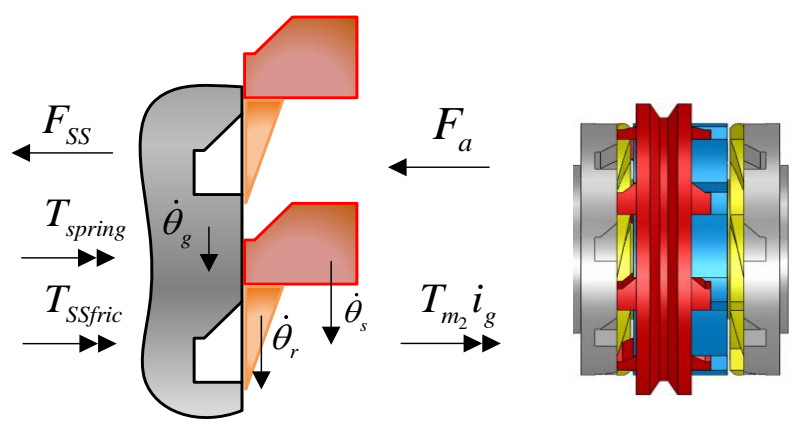

Fig. 8. The position of the Harpoon-shift components during the fourth stage.

Since a collision between the guide ring and the sleeve prongs takes place due to the speed discrepancy, the IMPACT function [24-25] is used to describe the collision dynamics. The contact force (normal force) consists of two parts, the spring and damping forces, and it can be calculated by

$$
F_{n}=K q^{n}+D \dot{q}
$$

where $K$ is the generalized stiffness coefficient, $q$ is the relative penetration depth, $n$ is the nonlinear exponent factor, $D$ is the damping coefficient, $\dot{q}$ is the relative normal contact speed. The damping coefficient can be computed by

$$
D=c_{\max } \operatorname{step}\left(q, q_{0}, h_{0}, q_{1}, h_{1}\right)
$$

where $c_{\max }$ is the maximum damping coefficient. The step function is given by

$$
\operatorname{step}\left(q, q_{0}, h_{0}, q_{1}, h_{1}\right)= \begin{cases}h_{0}, & \left(q \leq q_{0}\right) \\ h_{0}+\left(h_{1}-h_{0}\right) \Delta^{2}(3-2 \Delta), & \left(q_{0}<q<q_{1}\right) \\ h_{1} & \left(q \geq q_{1}\right)\end{cases}
$$

in the above expression, $q_{0}=0, h_{0}=0, h_{1}=1, \Delta=\left(q-q_{0}\right) /\left(q_{1}-q_{0}\right) . q_{1}$ is the maximum penetration depth, which corresponds to the maximum damping coefficient $c_{\max }$. The characteristic of the damping coefficient is displayed in Fig. 9.

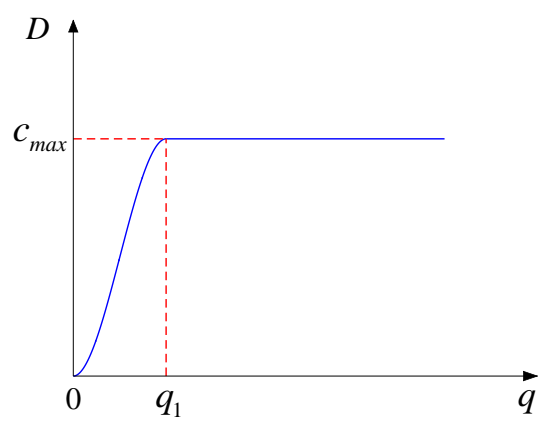

Fig. 9. The characteristic of damping coefficient [25].

The differential equations regarding this stage are

$$
J_{s}^{\prime} \ddot{\theta}_{s}=-\mu_{s g} F_{a} R_{m}-k_{2}\left(\theta_{s}-\theta_{g b}\right)-c_{2}\left(\dot{\theta}_{s}-\dot{\theta}_{g b}\right)-k_{s r}\left(\theta_{s}-\theta_{r}-\frac{2 \pi}{N}\right)^{n}-c_{s r}\left(\dot{\theta}_{s}-\dot{\theta}_{r}\right)
$$




$$
\begin{aligned}
& J_{e q}^{\prime} \ddot{\theta}_{g b}=T_{m_{2}} i_{g}-c_{s} \dot{\theta}_{g b}+k_{2}\left(\theta_{s}-\theta_{g b}\right)+c_{2}\left(\dot{\theta}_{s}-\dot{\theta}_{g b}\right) \\
& J_{g}^{\prime} \ddot{\theta}_{g}=\mu_{s g} F_{a} R_{m}+k_{r g}\left(\theta_{r}-\theta_{g}\right)+c_{r g}\left(\dot{\theta}_{r}-\dot{\theta}_{g}\right)-k_{1}\left(\theta_{g}-\theta_{m_{1}}\right)-c_{1}\left(\dot{\theta}_{g}-\dot{\theta}_{m_{1}}\right) \\
& J_{m_{1}}^{\prime} \ddot{\theta}_{m_{1}}=-T_{m_{1}}-c_{g} \dot{\theta}_{m_{1}}+k_{1}\left(\theta_{g}-\theta_{m_{1}}\right)+c_{1}\left(\dot{\theta}_{g}-\dot{\theta}_{m_{1}}\right) \\
& J_{r} \ddot{\theta}_{r}=k_{s r}\left(\theta_{s}-\theta_{r}-\frac{2 \pi}{N}\right)^{n}+c_{s r}\left(\dot{\theta}_{s}-\dot{\theta}_{r}\right)-k_{r g}\left(\theta_{r}-\theta_{g}\right)-c_{r g}\left(\dot{\theta}_{r}-\dot{\theta}_{g}\right) \\
& m_{s} \ddot{x}_{s}=0
\end{aligned}
$$

where $n$ is the nonlinear exponent factor $(n=2.2), N$ is the number of sleeve prongs $(N=8)$, $k_{s r}$ and $c_{s r}$ are the equivalent stiffness and damping coefficients, respectively, which correspond to $K$ and $D$ in Eq. 25.

Stage $5\left(\theta_{3}+\theta^{\prime} \leq \theta_{s}<\theta_{3}^{\prime}+\theta^{\prime}\right)$ :

The fifth stage is illustrated in Fig. 10. The prong begins to slide along the chamfer of the synchronizer groove and continue pushing the guide ring under the pressure from the shift fork. The collision between the guide ring and the sleeve prongs still exists throughout this phase.
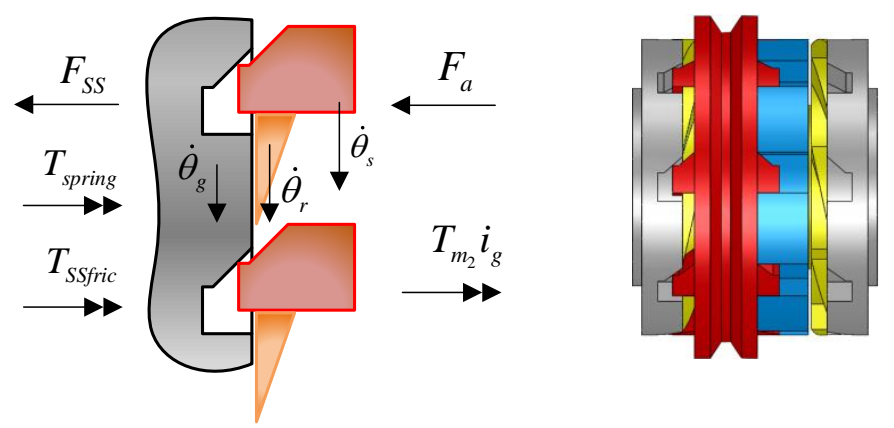

Fig. 10. The position of the Harpoon-shift components during the fifth stage.

The equations regarding this stage are:

$$
\begin{aligned}
J_{s}^{\prime} \ddot{\theta}_{s}= & F_{a} R_{m} \frac{1-\mu_{s}^{\prime} \tan \beta_{2}}{\tan \beta_{2}+\mu_{s}^{\prime}}-k_{2}\left(\theta_{s}-\theta_{g b}\right)-c_{2}\left(\dot{\theta}_{s}-\dot{\theta}_{g b}\right)-k_{s r}\left(\theta_{s}-\theta_{r}-\frac{2 \pi}{N}\right)^{n} \\
& -c_{s r}\left(\dot{\theta}_{s}-\dot{\theta}_{r}\right) \\
J_{e q}^{\prime} \ddot{\theta}_{g b}= & T_{m_{2}} i_{g}-c_{s} \dot{\theta}_{g b}+k_{2}\left(\theta_{s}-\theta_{g b}\right)+c_{2}\left(\dot{\theta}_{s}-\dot{\theta}_{g b}\right) \\
J_{g}^{\prime} \ddot{\theta}_{g}= & -F_{a} R_{m} \frac{1-\mu_{s}^{\prime} \tan \beta_{2}}{\tan \beta_{2}+\mu_{s}^{\prime}}+k_{r g}\left(\theta_{r}-\theta_{g}\right)+c_{r g}\left(\dot{\theta}_{r}-\dot{\theta}_{g}\right)-k_{1}\left(\theta_{g}-\theta_{m_{1}}\right)-c_{1}\left(\dot{\theta}_{g}-\dot{\theta}_{m_{1}}\right) \\
J_{m_{1}}^{\prime} \ddot{\theta}_{m_{1}}= & -T_{m_{1}}-c_{g} \dot{\theta}_{m_{1}}+k_{1}\left(\theta_{g}-\theta_{m_{1}}\right)+c_{1}\left(\dot{\theta}_{g}-\dot{\theta}_{m_{1}}\right) \\
J_{r} \ddot{\theta}_{r}= & k_{s r}\left(\theta_{s}-\theta_{r}-\frac{2 \pi}{N}\right)^{n}+c_{s r}\left(\dot{\theta}_{s}-\dot{\theta}_{r}\right)-k_{r g}\left(\theta_{r}-\theta_{g}\right)-c_{r g}\left(\dot{\theta}_{r}-\dot{\theta}_{g}\right) \\
m_{s} \ddot{x}_{s}= & F_{a}-F_{a}^{\prime \prime}
\end{aligned}
$$


where $\beta_{2}$ is chamfer angle of the groove, $\mu_{s}^{\prime}$ is the chamfer friction coefficient, $F_{a}^{\prime \prime}$ is axial component of the normal force when the sleeve prong contacts the chamfer surface of the groove. Detailed calculation of $F_{a}^{\prime \prime}$ is shown in Appendix A. Similar to the stage 2, there is also a constraint equation between the axial and tangential velocities, i.e. $\dot{x}_{s}=\left(\dot{\theta}_{s}-\dot{\theta}_{g}\right) R_{\text {out }} \cot \beta_{2}$. The chamfer friction calculation in Eq. 34 is similar to the calculation process in Eq. 13 shown in Appendix B.

Stage $6\left(\theta_{3}^{\prime}+\theta^{\prime} \leq \theta_{s} \leq \theta_{4}\right)$ :

The sixth stage is shown in Fig. 11. This stage starts with the prong of the Harpoon-shift sleeve contacting the flat flank of the external groove of the synchroniser groove. During this stage, the prong of the sleeve is pushed by the shift fork to the bottom of the external groove of the dog gear.
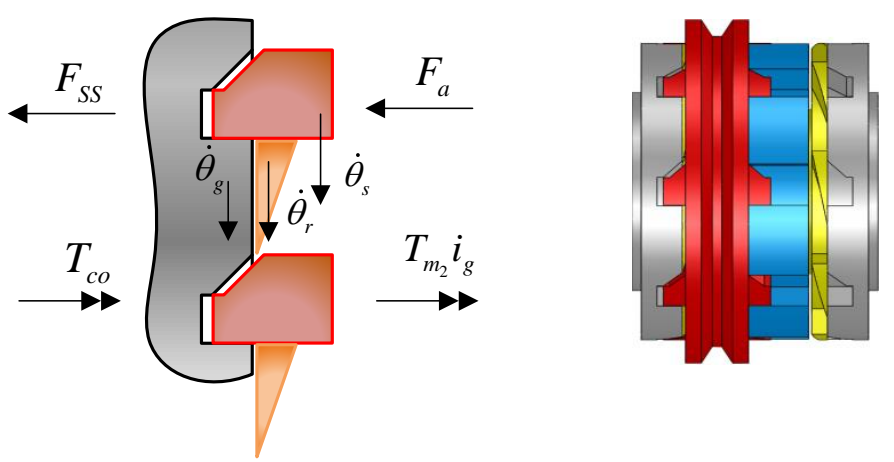

Fig. 11. The position of the Harpoon-shift components during the sixth stage.

Since the collision between the dog gear and the sleeve prongs takes place during this phase, the IMPACT function is applied again to describe the dynamics of the collision. Therefore, the differential equations are

$$
\begin{aligned}
J_{s}^{\prime} \ddot{\theta}_{s}= & -k_{s g}\left(\theta_{s}-\theta_{g}-\theta_{4}\right)^{n}-c_{s g}\left(\dot{\theta}_{s}-\dot{\theta}_{g}\right)-k_{s r}\left(\theta_{s}-\theta_{r}-\frac{2 \pi}{N}\right)^{n}-c_{s r}\left(\dot{\theta}_{s}-\dot{\theta}_{r}\right)-k_{2}\left(\theta_{s}-\theta_{g b}\right) \\
& -c_{2}\left(\dot{\theta}_{s}-\dot{\theta}_{g b}\right) \\
J_{e q}^{\prime} \ddot{\theta}_{g b}= & T_{m_{2}} i_{g}-c_{s} \dot{\theta}_{g b}+k_{2}\left(\theta_{s}-\theta_{g b}\right)+c_{2}\left(\dot{\theta}_{s}-\dot{\theta}_{g b}\right) \\
J_{g}^{\prime} \ddot{\theta}_{g}= & k_{s g}\left(\theta_{s}-\theta_{g}-\theta_{4}\right)^{n}+c_{s g}\left(\dot{\theta}_{s}-\dot{\theta}_{g}\right)+k_{r g}\left(\theta_{r}-\theta_{g}\right)+c_{r g}\left(\dot{\theta}_{r}-\dot{\theta}_{g}\right)-k_{1}\left(\theta_{g}-\theta_{m_{1}}\right) \\
& -c_{1}\left(\dot{\theta}_{g}-\dot{\theta}_{m_{1}}\right) \\
J_{m_{1}}^{\prime} \ddot{\theta}_{m_{1}}= & -T_{m_{1}}-c_{g} \dot{\theta}_{m_{1}}+k_{1}\left(\theta_{g}-\theta_{m_{1}}\right)+c_{1}\left(\dot{\theta}_{g}-\dot{\theta}_{m_{1}}\right) \\
J_{r} \ddot{\theta}_{r}= & k_{s r}\left(\theta_{s}-\theta_{r}-\frac{2 \pi}{N}\right)^{n}+c_{s r}\left(\dot{\theta}_{s}-\dot{\theta}_{r}\right)-k_{r g}\left(\theta_{r}-\theta_{g}\right)-c_{r g}\left(\dot{\theta}_{r}-\dot{\theta}_{g}\right) \\
m_{s} \ddot{x}_{s}= & F_{a}-F_{L t 2}
\end{aligned}
$$

where $k_{s g}$ and $c_{s g}$ are the equivalent stiffness and damping coefficients, respectively, which correspond to $K$ and $D$ in Eq. 25. $F_{L t 2}$ is the reaction force when the sleeve prongs contact the surface of the groove bottom of dog gear, which is shown in Appendix A in detail. 
Stage $7\left(\theta_{4}<\theta_{s}\left(\theta_{4} \approx \theta_{s}\right) \& \dot{\theta}_{s}=\dot{\theta}_{r}=\dot{\theta}_{g}\right)$ :

The seventh stage is illustrated in Fig. 12. The phase ends with the sleeve reaching the final position of the synchronization process with the splines fully meshed with the dog gear. Positive locking can be achieved between the prong and groove through deliberate undercutting of the two features on the components or the constant pushing force from the shift fork. Since the Harpoon-shift is locked up, the angular velocities of the sleeve, guide ring, and dog gear are identical, i.e., $\dot{\theta}_{s}=\dot{\theta}_{r}=\dot{\theta}_{g}$.
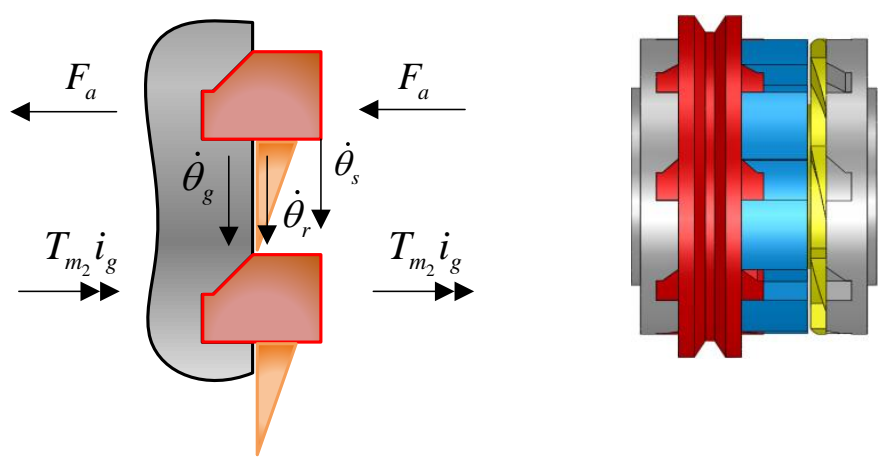

Fig. 12. The position of the Harpoon-shift components during the seventh stage.

The differential equations referring to this stage of the process are as follows:

$$
\begin{aligned}
& \left(J_{s}^{\prime}+J_{g}^{\prime}+J_{r}\right) \ddot{\theta}_{s}=-k_{1}\left(\theta_{g}-\theta_{m_{1}}\right)-c_{1}\left(\dot{\theta}_{g}-\dot{\theta}_{m_{1}}\right)-k_{2}\left(\theta_{s}-\theta_{g b}\right)-c_{2}\left(\dot{\theta}_{s}-\dot{\theta}_{g b}\right) \\
& J_{m_{1}}^{\prime} \ddot{\theta}_{m_{1}}=-T_{m_{1}}-c_{g} \dot{\theta}_{m_{1}}+k_{1}\left(\theta_{g}-\theta_{m_{1}}\right)+c_{1}\left(\dot{\theta}_{g}-\dot{\theta}_{m_{1}}\right) \\
& J_{e q}^{\prime} \ddot{\theta}_{g b}=T_{m_{2}} i_{g}-c_{s} \dot{\theta}_{g b}+k_{2}\left(\theta_{s}-\theta_{g b}\right)+c_{2}\left(\dot{\theta}_{s}-\dot{\theta}_{g b}\right) \\
& m_{s} \ddot{x}_{s}=0
\end{aligned}
$$

It is worth noting that, after engagement, the compression energy in the torque spring will not be released until next gear shifting event starts. When next shifting begins, the sleeve will move axially from the engaged position to the neutral position. Simultaneously, the guide ring will rotate back to its initial position under the restoring force of the compressed torque spring, where the guide ring blocks the grooves of the dog gear to prevent premature locking if this gear is selected again.

\section{Simulation results and related analysis}

The engaging process of the Harpoon-shift mechanism is simulated in MATLAB/SIMULINK, and the numerical solver ODE45 is applied during the simulation at a maximum time step of $5 \times 10^{-6}$. The main parameters used in the simulation are listed in Appendix C.

\subsection{Simulation results of engagement.}

Fig. 13 shows the speed responses of all the rotating degrees of freedom (DOFs) of the model and the status (stage $1 \sim 7$ ) of the Harpoon-shift during the engaging process. Particularly, in the stage 4 , the sleeve prongs start to rotate the guide ring and the speed of the latter increases dramatically. The torque spring then is compressed due to the relative angular displacement between the guide ring and the dog 
gear. It can be observed that the motor 1 is static, even though the springs are being compressed by the guide ring during the stage 4 and 5 , and this results from the fact that the torque generated by the torque spring compression is less than the resistance torque provided by the motor 1 . However, when the torque due to collision between the sleeve and groove ring in the stage 6 is larger than the resistance torque, the dog gear will be accelerated quickly, starting from point B. Then, the sleeve speed matches the dog gear speed, indicating that the engaging process enters stage 7 (locked-up stage). During this phase, the dog gear, guide ring, and sleeve (including the sleeve hub) rotate at the same speed. Thus the curves of these three DOFs merge into one curve as shown in Fig. 13. The acceleration discrepancy between the sleeve and the dog gear prior to the locked-up phase causes torsional oscillations to the whole mechanical system, but then the speed amplitudes reduce quickly because of the damping in the system.

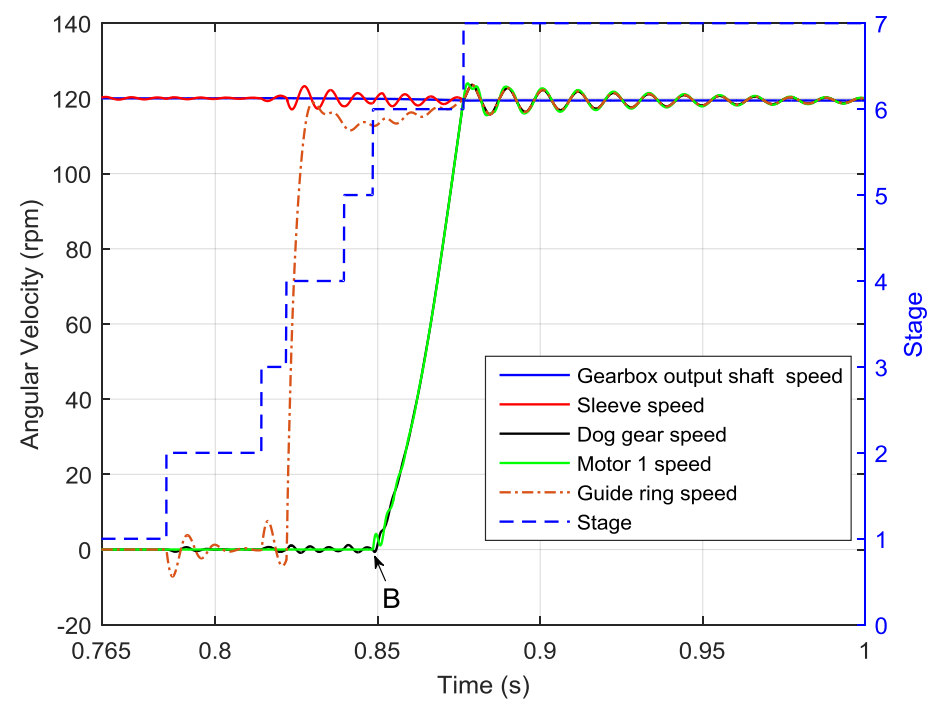

Fig. 13. Simulated speed responses and status: the initial velocities of dog gear, guide ring and motor 1 are zero, while the initial speed of sleeve (including sleeve hub) and gearbox output shaft are $120 \mathrm{rpm}$; the spring of $1 \mathrm{~mm}$ wire is used during engagement of Harpoon-shift.

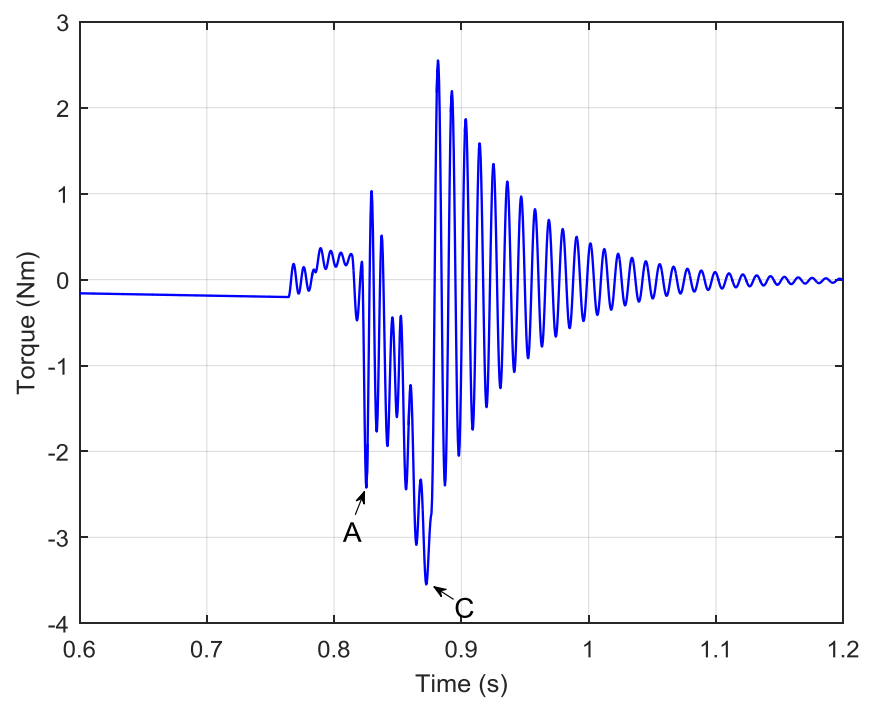

Fig. 14. Simulated torque response of input shaft 
Fig. 14 displays the torque response of the input shaft. There are two crucial points during engagement: point $\mathrm{A}$ is the local torque peak $(-2.4 \mathrm{Nm})$ when the torque spring is being compressed to accelerate the output shaft up to the target speed, and point $C$ is the torque peak $(-3.6 \mathrm{Nm})$, indicating that the speed synchronization is finished. After engagement, the torque vibration is damped by the damping in the system.

The speed responses of Harpoon-shift under the speed difference of $300 \mathrm{rpm}$ and $500 \mathrm{rpm}$ are shown in Fig. 15. It is obvious that the amplitudes of the speed response will increase as the speed difference increases, but the engagement duration reduces significantly.
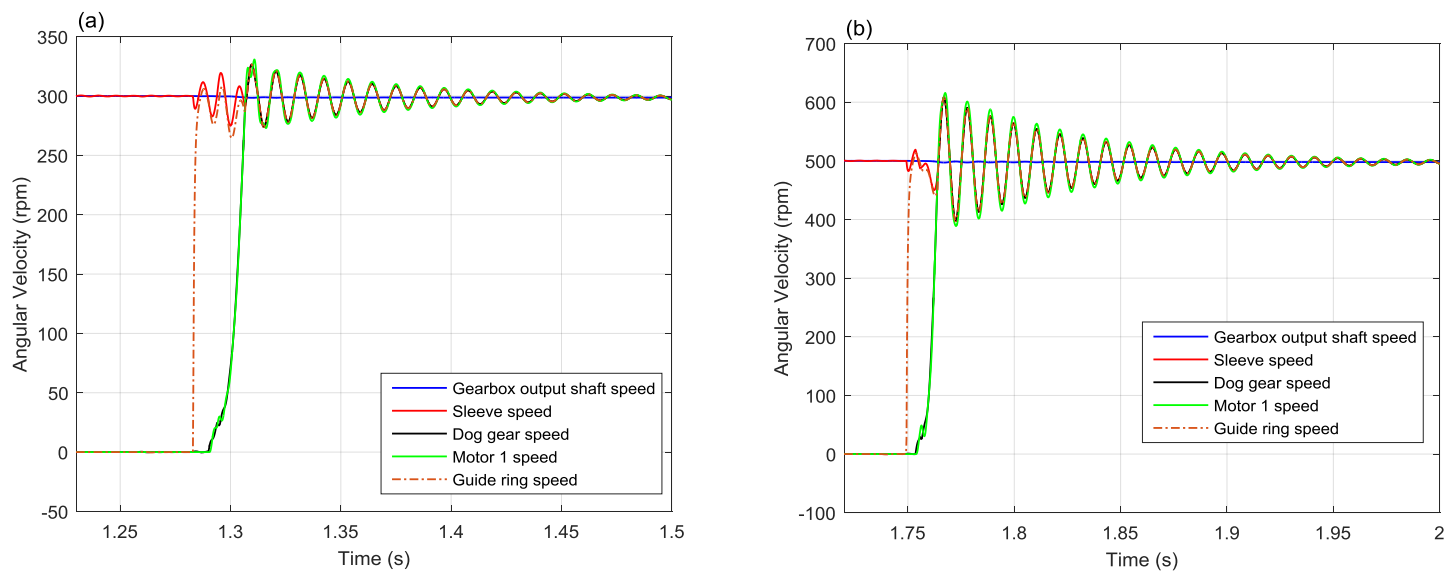

Fig. 15. Simulated speed responses of engagement under two speed differences: (a) $300 \mathrm{rpm}$, (b) $500 \mathrm{rpm}$.

\subsection{Influence of rotating inertia, speed and speed difference}

In this section, further study is carried out to quantitatively investigate the impact of the rotating inertia, speed and speed difference on the torsional oscillation, based on the dynamic model established in the previous section. As illustrated in Section 1, the Harpoon-shift mechanism relies on relative speed difference between sleeve hub and constant mesh gear. The sleeve rotates the guide ring to compress the spring, which provides a torque to eliminate the residual relative speed before the sleeve finishes engagement. For the cases of low speed difference, the input side of Harpoon shift cannot supply sufficient energy to open the guide ring. However, as the rotating inertia of the input side increases, engagement can be successfully completed at much lower speed difference due to the fact that the input side with larger inertia stores more kinetic energy to push the guide ring to the open position.

Based to the above consideration, some parameters and initial conditions in the simulation need to be modified in the study. For instance, the rotating inertia of the two motors will be increased and there is an initial speed for the dog gear before engagement starts. Besides, the output torques of the two motors are set to zero during engagement. In this section, research focuses on the Harpoon-shift with the spring of $1 \mathrm{~mm}$ wire.

\subsubsection{Impact of rotating inertia}

In this section, the rotating inertia of motor 2 is increased by a factor of ten, while the motor 1 inertia increases to 2.5, 5 and 10 times as compared with the initial value. In the simulation, the initial speeds of the motor $1, \operatorname{dog}$ gear and the guide ring are $1000 \mathrm{rpm}$ (i.e. $\dot{\theta}_{m_{1}}=\dot{\theta}_{g}=\dot{\theta}_{r}=1000 \mathrm{rpm}$ ) and the speed difference is $10 \mathrm{rpm}$ (i.e. $\dot{\theta}_{s}=\dot{\theta}_{g b}=1010 \mathrm{rpm}$ ). The variation of torque transmitted by the mechanical coupling 2 is displayed in Fig. 16. As the inertia of motor 1 increases, the peak-to-peak amplitude of 
the torque vibration rises accordingly; the figure also intuitively shows that the engagement duration increases. Table 1 presents the overall engagement duration of Harpoon-shift with different inertia of motor 1 . The simulation results show that the rotating inertia significantly influences the torque oscillation and engagement duration.

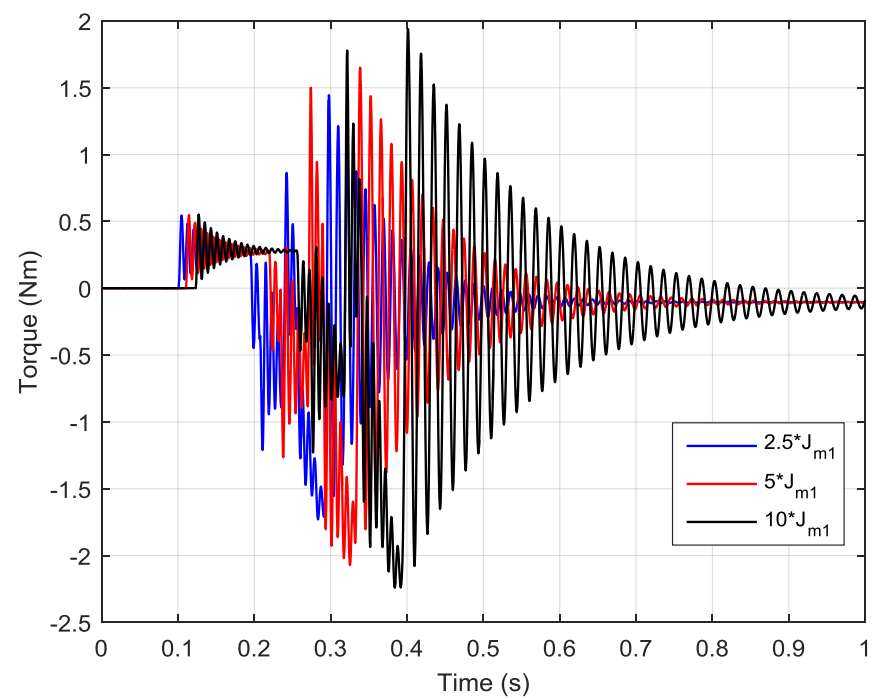

Fig. 16. Simulation results: torque responses under various rotating inertia of motor 1.

\section{Table 1}

Engagement duration under various rotating inertia of motor 1

\begin{tabular}{ll}
\hline Inertia & Whole duration $(\mathrm{ms})$ \\
\hline $2.5 J_{m_{1}}$ & 288.26 \\
$5 J_{m_{1}}$ & 327.89 \\
$10 J_{m_{1}}$ & 389.62 \\
\hline
\end{tabular}

\subsubsection{Impact of rotating speed}

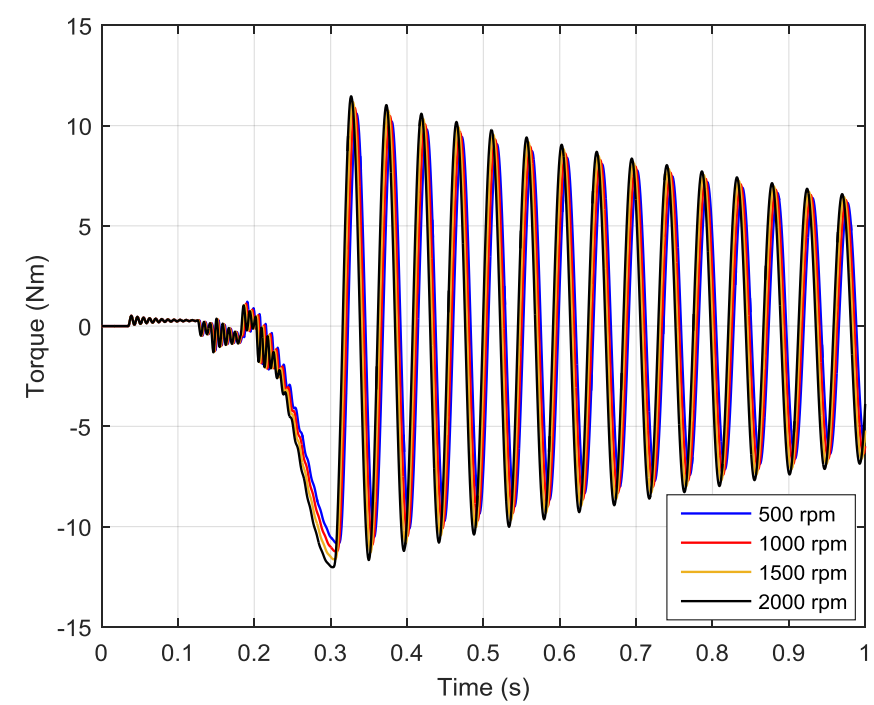

Fig. 17. Simulation results: torque responses under various rotating speeds. 
In this section, research is conducted to study the influence of rotating speed on the torsional vibration. The motor 1 speed is varied at $500 \mathrm{rpm}$ increments from $500 \mathrm{rpm}$ to $2000 \mathrm{rpm}$ and engagement simulation of Harpoon-shift is performed under the same speed difference (50 rpm). In the simulation, the rotating inertia of motor 1 is increased by a factor of 100 and motor 2 by a factor of 10 . The torque variation during engaging phase is shown in Fig. 17. These results lead to a conclusion that the rotating speed has almost no impact on the torsional vibration.

\subsubsection{Impact of speed difference}

Study in this section focuses on the influence of relative speed difference between sleeve hub and target gear on the torsional oscillation of the Harpoon-shift mechanism. In the simulation, the rotating inertia of motor 1 is increased by a factor of 100 and motor 2 by a factor of 10 , and the rotating speed of input side is $1000 \mathrm{rpm}$. Fig. 18 shows the torque responses of Harpoon-shift engagement under speed reference of 10,30, and $50 \mathrm{rpm}$. As the relative speed between the dog gear and sleeve increases, torque amplitude increases, but the engagement duration reduces significantly. This indicates that the post lockup vibrations as well as the duration of engaging process are significantly affected by the speed difference. In particular, for the case of $50 \mathrm{rpm}$ speed reference, the Harpoon-shift is open during the stage 4 and 5 , and the torque vibrates at $123.8 \mathrm{~Hz}$, while in the locked-up phase, the vibrational frequency is $21.7 \mathrm{~Hz}$.

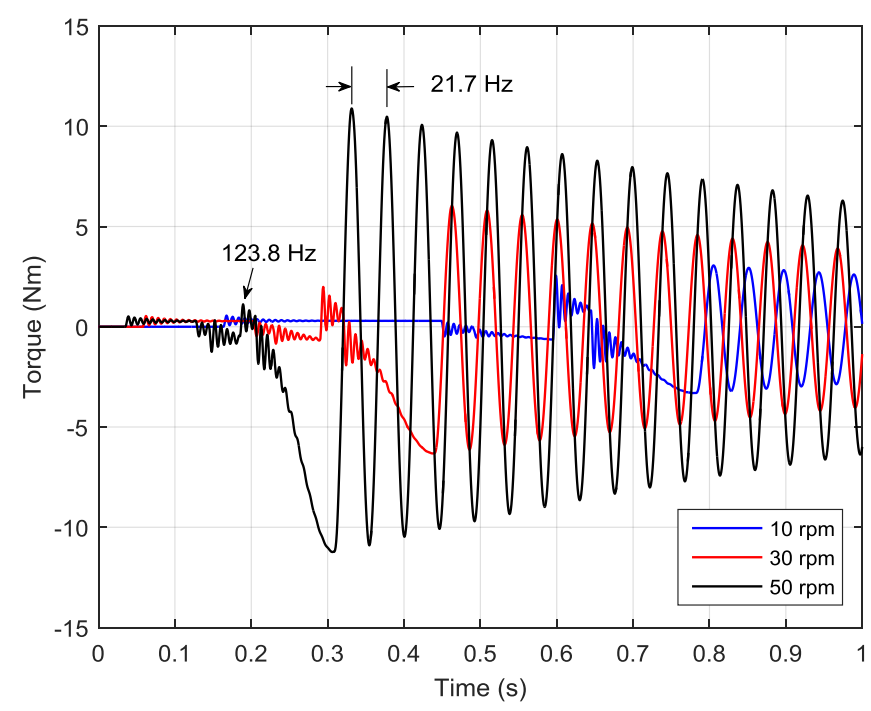

Fig. 18. Simulation results: torque responses under various speed differences.

Fig. 19 displays the sleeve axial displacement during engagement under various speed differences. It is found that the sleeve movement is blocked at $5 \mathrm{~mm}$ and $10 \mathrm{~mm}$, corresponding to the positions of front faces of the guide ring and dog gear, respectively. In addition, it is worth noting that the prong does not always contact the front face of the guide ring. Under some circumstances, the prong directly contacts the guide ring chamfer or the front face of the groove ring, depending on the relative angular alignment between the sleeve and the guide ring; in these cases, the sleeve axial movement will be blocked only at $10 \mathrm{~mm}$.

Additionally, it should be noted that the prongs touch the groove bottom (engaged status) before the Harpoon-shift finishes the speed synchronization. This indicates that when the sleeve reaches the maximum engaging distance $(18 \mathrm{~mm})$, there is still speed discrepancy between the dog gear and sleeve. 
When the speed synchronization completes, the engaging process enters the locked-up phase (stage 7). The total engagement duration of Harpoon-shift under different speed differences is presented in Table 2.

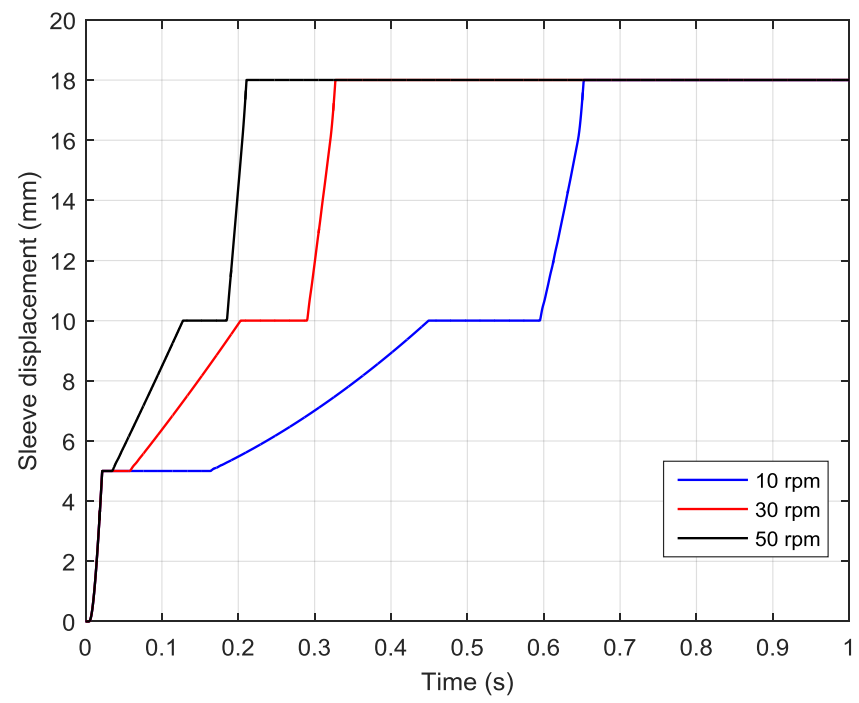

Fig. 19. Simulation results: axial displacement of sleeve during engagement under various speed differences.

\section{Table 2}

Engagement duration under various speed differences

\begin{tabular}{ll}
\hline Speed difference $(\mathrm{rpm})$ & Whole duration $(\mathrm{ms})$ \\
\hline 10 & 778.67 \\
30 & 436.08 \\
50 & 304.88 \\
\hline
\end{tabular}

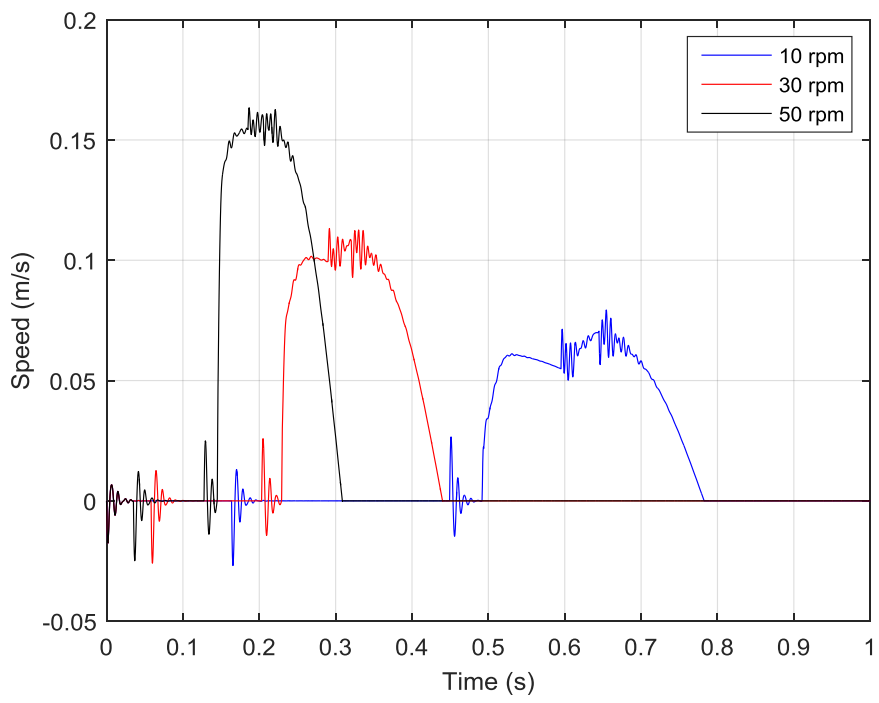

Fig. 20. Simulation results: spring compression rate under various speed differences. 
Fig. 20 presents the spring compression rate. While the speed difference increases, the spring compressing rate increase correspondingly. Especially, when the speed difference reaches $50 \mathrm{rpm}$, the maximum compression speed is up to $0.163 \mathrm{~m} / \mathrm{s}$. Nevertheless, if the spring is compressed too fast, spring fatigue phenomenon will occur, leading to the engagement failure of the Harpoon-shift mechanism. Hence, taking into account the factors of extending the spring durability and declining the torsional vibration during engagement, lower speed difference would be preferred, but this will increase the overall engagement duration. It should be noted that there is negative rate of spring compression in the simulation results, which occurs during the stage 2 due to the collision between the guide ring and the limitation mechanism of dog gear. The negative speed thus denotes the relative normal contact speed, similar to the parameter $\dot{q}$ in Eq. (25).

\section{Experimental results of typical engagement}

\subsection{Experimental setup}

The purpose of these tests are to evaluate the functional requirements of the mechanism, particularly studying the impact of varying differential speed and spring stiffness on system capacity to successfully engage. Fig. 21(a) presents the assembled Harpoon-shift prototype used in testing, with the sleeve shown in the disengaged position. Fig. 21(b) presents the functional layout of the test rig, including drive motor, inertial components, shift mechanism, resistance load, and speed and torque sensors. Fig. 21(c) shows the integrated testing rig.

The motor control unit (MCU) is a variable speed drive to control the four-pole induction motor (i.e. motor 2). Motor 2 drives the output side of the test gearbox via an intermediate shaft that includes a strain gauge-type torque sensor. The intermediate shaft is connected to the input shaft of the test unit (Harpoon-shift) via the mechanical coupling 2, and the output shaft is connected to the motor 1 through the mechanical coupling 1 . The motor 2 and gearbox provide a simulated load representing the whole vehicle inertia, for these tests the input side of the test unit is held at constant speed and the output side of the test unit is synchronised to the input with the Harpoon-shift mechanism. Motor 1 is a DC motor used to provide a resistance load during testing.

The Harpoon-shift does not need a friction force to accomplish the engagement. Furthermore, it does not require high loads that are associated with friction clutches a pneumatic cylinder is used for actuation. The selected actuator has a $10 \mathrm{~mm}$ bore and $25 \mathrm{~mm}$ stroke; it is controlled by an on/off switch with a nominal pressure of $600 \mathrm{KPa}$. This produces a peak force of $47 \mathrm{~N}$ during actuation. The pneumatic cylinder is controlled by a flow valve to engage and release the mechanism.

For the collection of the testing results, two speed sensors are installed to record the speed of the input and the output shafts (on the end of the two motor shafts), and a torque sensor is installed between the reduction gear and test piece to record the variation of the torque during the engagement of the Harpoonshift. Data signals are collected through a Multifunction I/O Device from National Instruments, data is collected through a NI-DAQmx driver and Measurement \& Automation Explorer (MAX) 
configuration utility to simplify configuration and measurement. Data is then logged through LabVIEW.

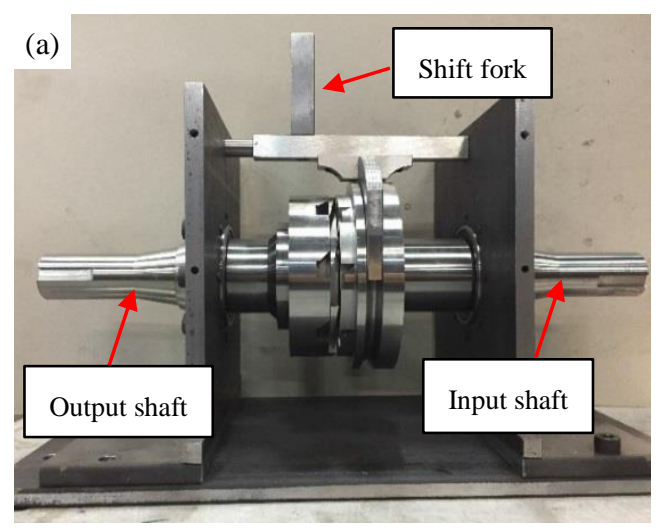

(b)
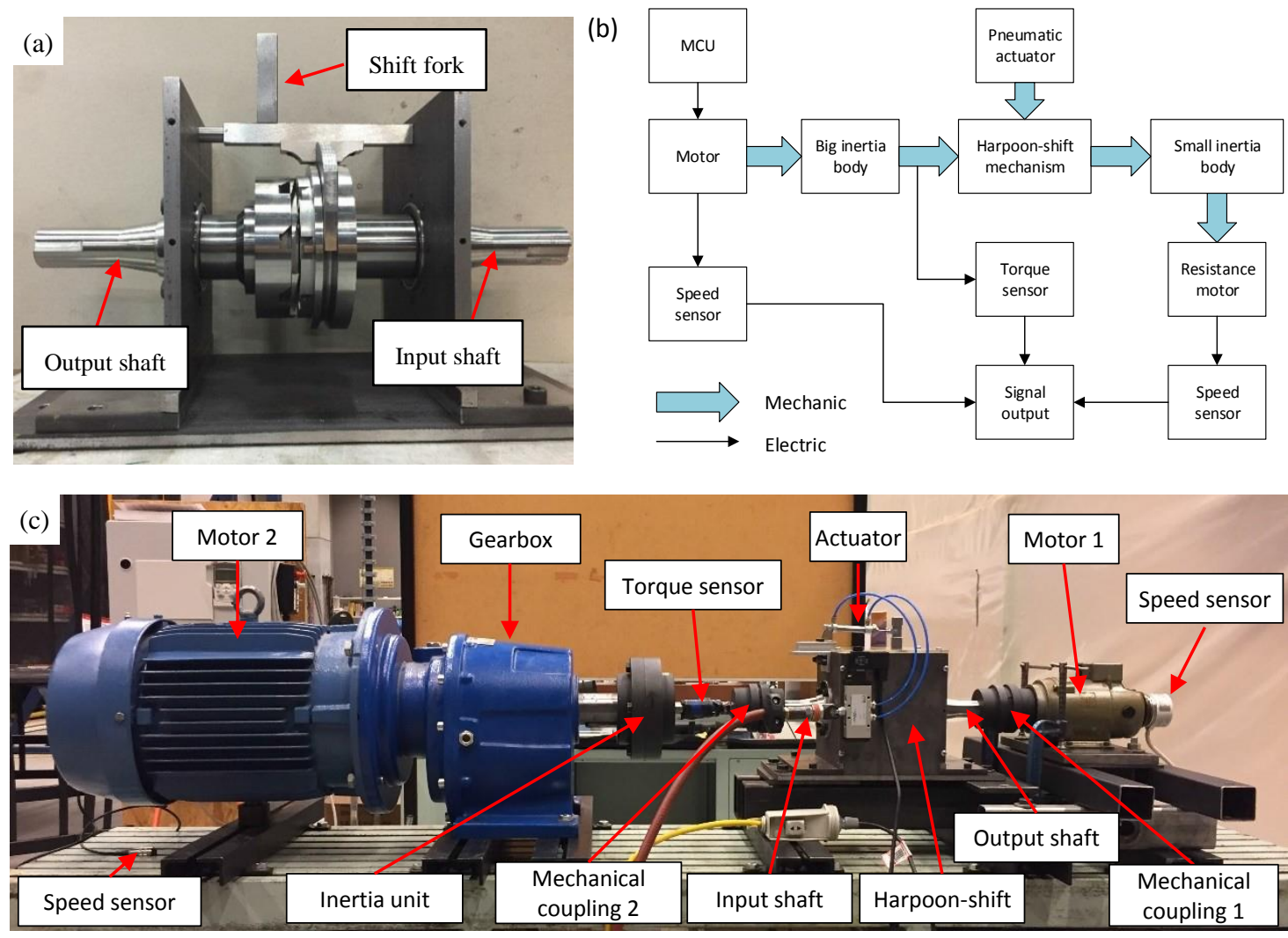

Fig. 21. Test rig: (a) The working components of the Harpoon-shift prototype, (b) Schematic of the Harpoon-shift test rig, and (c) shows the complete assembly prior to testing.

\subsection{Testing variables}

Previously, both the spring stiffness and differential speed were identified as the two main variables that will still be evaluated during testing. Test pieces for the springs are produced by bending straight springs to be installed in the internal groove of the synchroniser groove, as shown in Fig. 22. For the testing of the Harpoon-shift, four different spring arrangements are prepared as shown in Table 3.
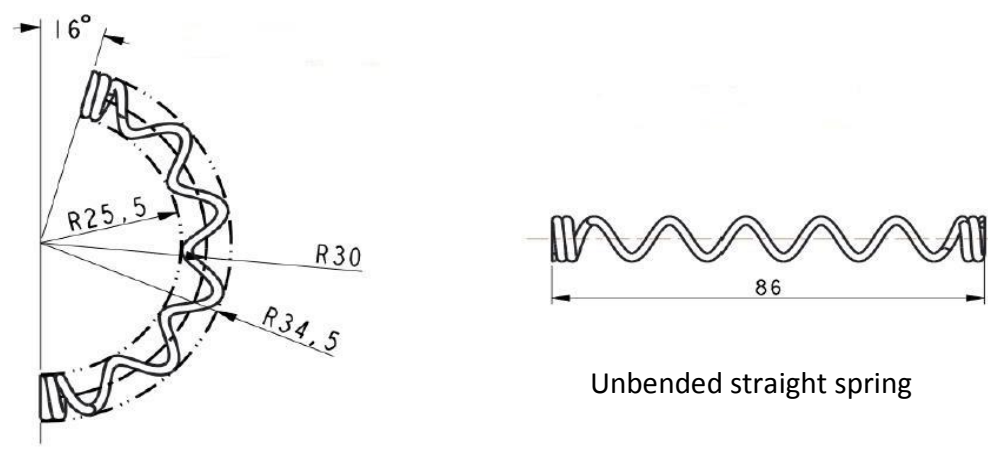

Unbended straight spring

Bended spring

Fig. 22. The unbended straight spring and the bended spring. 
Table 3

Spring characteristics for testing

\begin{tabular}{lllll}
\hline Test specimen & 1 & 2 & 3 & 4 \\
\hline Spring wire diameter $(\mathrm{mm})$ & 1 & 1.25 & 1.4 & 1.6 \\
Spring coefficient $k_{s 1}(\mathrm{~N} / \mathrm{m})$ & 1 & 2500 & 4000 & 8000 \\
\hline
\end{tabular}

For testing variation of overall speed in the system, it is assumed that as the vehicle is significantly larger than the net inertia of the system being investigated, it is not necessary to consider the total speed of the system, just the differential speed. A particular advantage of this layout is that this technique also minimise the impact of losses in the actuation process, and closely represents the ideal engagement case. For speed studies, the primary motor is varied at $10 \mathrm{rpm}$ increments from $10 \mathrm{rpm}$ up to $500 \mathrm{rpm}$ from rest. The output side of the rig has an initial speed of zero, and the kinetic energy change is measured from the $500 \mathrm{rpm}$ speed difference.

\subsection{Typical engagement}

In the beginning of the testing, the input speed of the Harpoon-shift prototype is given with a determined value and the output shaft is kept motionless by the DC motor (motor 1). Thus, the speed difference is equal to the value of the input speed of the prototype. After the engagement of the Harpoon-shift, the change of the input torque and the output speed are examined by means of the torque sensor and speed sensors. An example of engagement is shown in Fig. 23. The process of engagement is observed at three crucial points. Point A in Fig. 23 indicates the sleeve is rotating the guide ring rapidly to compress the torque spring, generating the local torque peak, Point B is where the sleeve prongs and guide ring engage, accelerating the stationary shaft up to the target speed, and Point $\mathrm{C}$ demonstrates the final engagement condition with speed synchronisation completed. The transition from A to B takes approximately $200 \mathrm{~ms}$ and results in no appreciable change in the shaft torque, the transition from B to $\mathrm{C}$ is shorter, less than $100 \mathrm{~ms}$, and results in the stationary shaft being accelerated up to the target speed of $120 \mathrm{rpm}$. The input torque results demonstrate that whilst there is a rapid synchronisation to the target speed, there is only a minor increase in peak torque, from -1.5 to $-2 \mathrm{Nm}$, indicating that there is not a substantial load on the system as the spring torque synchronises the two shafts. Furthermore, the lack of reduction in input torque during the engagement also suggests that the mechanism will have limited impact in terms of vehicle noise, vibration and harshness.

It should be noted that the oscillation and damping are obvious in the simulated torque response in Figs. 17 and 18, which are different from the torque response of input shaft in Fig. 23. There are several reasons to account for the difference between the simulation and experimental results. First, as mentioned in Section 4.2, both the rotating inertia of motor 1 and motor 2 are significantly increased to investigate the inertia influence, leading to larger torsional vibration amplitude during engagement. Additionally, as mentioned in Section 3, the clearance between the rubber insert and mechanical components of the mechanical couplings, as well as the gear set clearance, is not considered in the simulation, but actually the testing results include substantial clearance influence. Third, there is noise in the testing result shown in Fig. 23. Although the damping effect is not obvious in Fig.23, the point $\mathrm{C}$, the torque peak, is not difficult to be identified. 


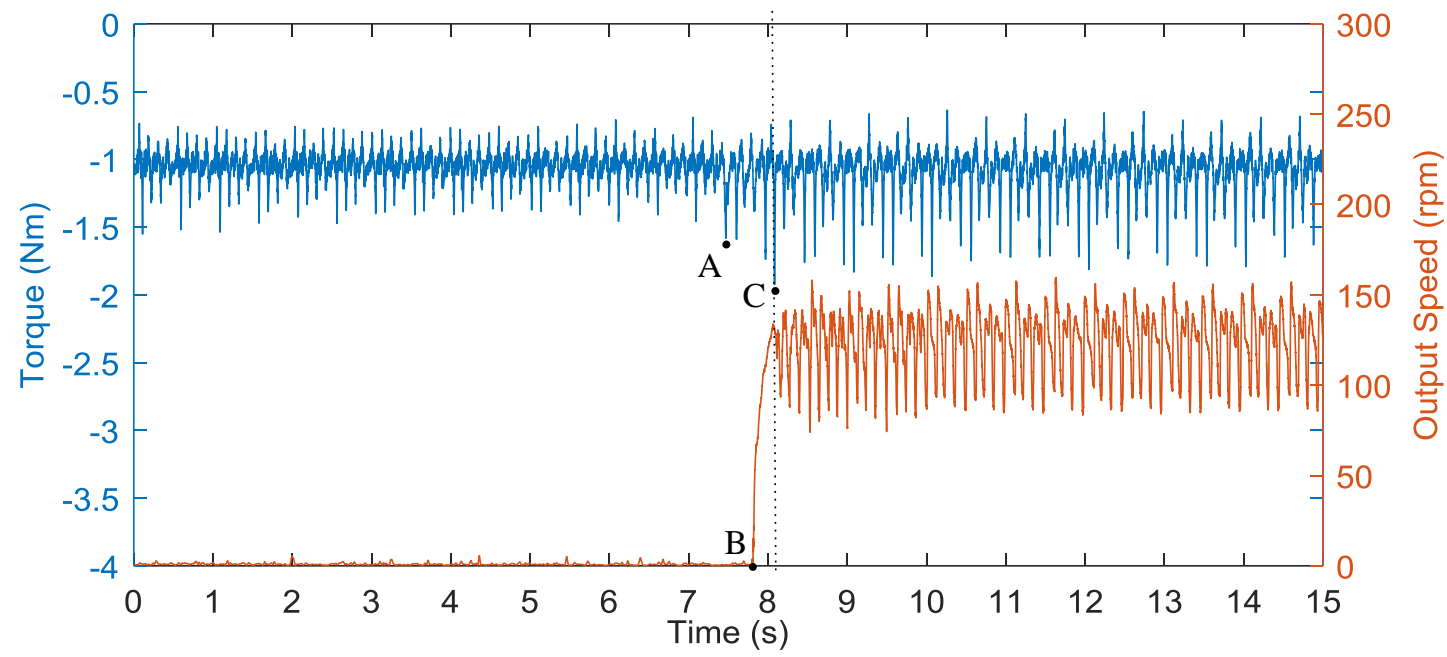

Fig. 23. Output shaft speed and input shaft torque of the Harpoon-shift during the engagement.

In addition, it can be found that there are differences in the values of the points $\mathrm{A}$ and $\mathrm{C}$ between the simulation and experimental results shown in Fig. 14 and 23, respectively. One reason is that the simulation is based on the assumption that the clearance effect is ignored. Thus, the simulated torque response is ideal. Another reason may be that the sampling frequency of the torque sensor used in the test bench is too low to capture the torque peak with high accuracy.

Fig. 24 shows the testing speed response of motor 1 under two speed differences during engagement. By comparing Fig. 15(a) with 24(a), Fig. 15(b) with 24(b), it can be found that the speed response of motor 1 computed by the mathematic model basically matches the testing results. Also, and comparing Fig. 13 and14 with Fig. 23, the key points (i.e., A, B and C) are basically matched, despite of the difference as discussed previously. This indicates that the model can reasonably represent the physical prototype of Harpoon-shift.
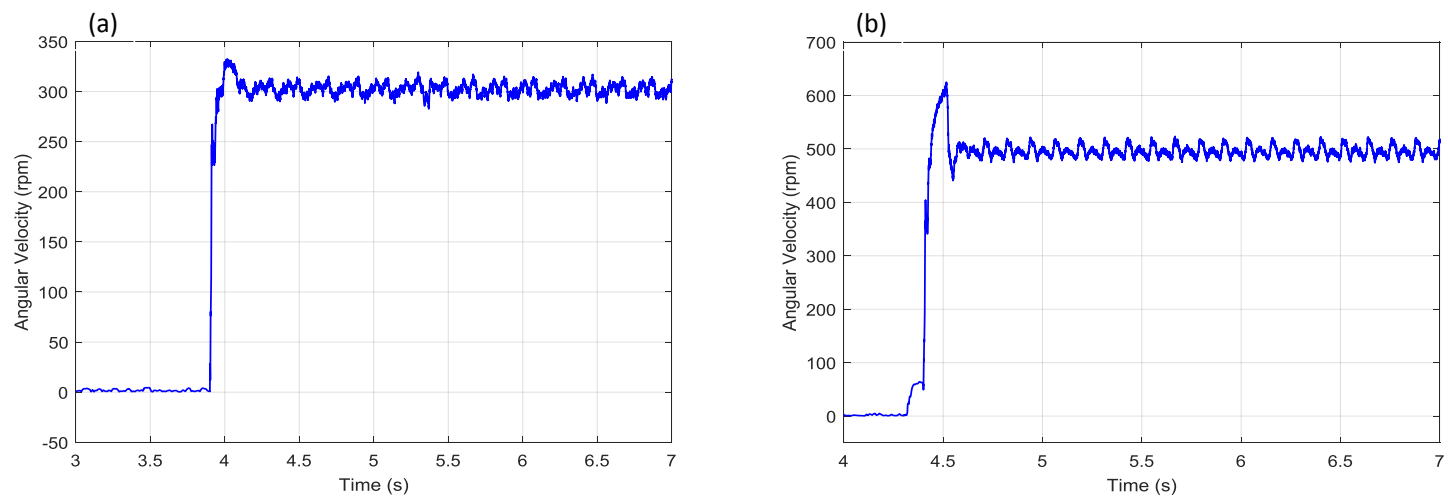

Fig. 24. Testing result of motor 1 speed under two speed differences: (a) $300 \mathrm{rpm}$, (b) $500 \mathrm{rpm}$. 


\subsection{Overall testing results for variation of spring stiffness and speed}

This section presents the experimental results evaluating the use of selected spring stiffnesses against differential speed. Using the same test rig as detailed in Section 5.1 each of the four different spring stiffness are tested with variation of input speed.

Fig. 25 (a) presents the peak torque values at the input shaft of the prototype with the springs of $1 \mathrm{~mm}$ wire in the test rig under the different speed differences. The results demonstrate a trend of increasing peak torque with increasing differential speed. These results are consistent with fundamental theories presented in Eq. (1) to (3), where higher speeds will produce larger spring compression and therefore larger torques. These results also demonstrate that there is a minimum speed threshold required to overcome the spring and complete engagement. Results at or below $80 \mathrm{rpm}$ do not successfully engage. Again, this is an expected characteristic of the system, with the guide ring not being capable of moving to the open position. Thus, the mechanism is demonstrated to effectively engage within expected characteristics. It shows that for lower speed events there is insufficient energy from the input side to open the guide ring and minimal torque is transmitted through the system. This is evidenced by the low torque readings at speeds less than $80 \mathrm{rpm}$.
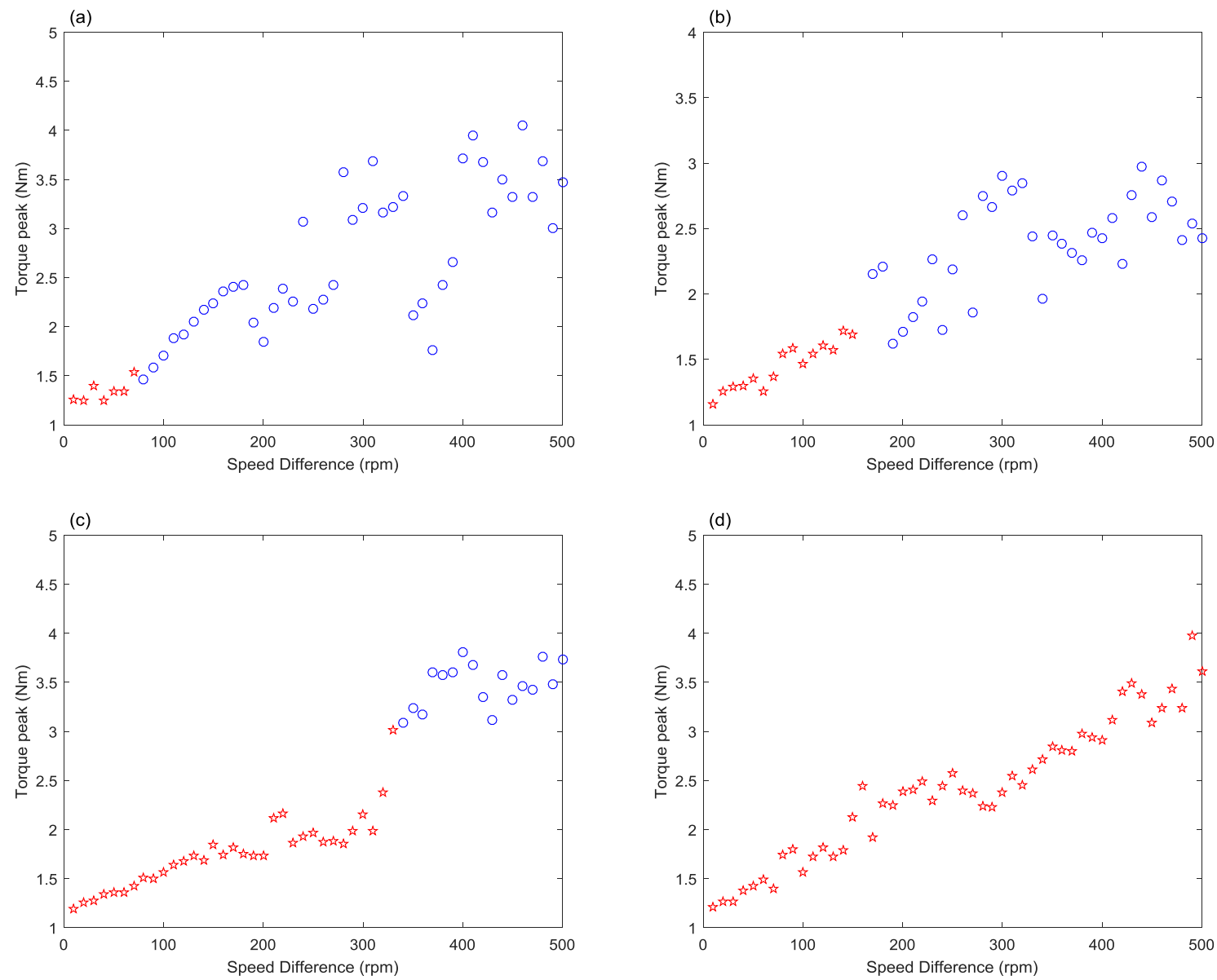

Fig. 25. (a) Torque peaks during the engagement of the Harpoon-shift with the spring of $1 \mathrm{~mm}$ wire, (b) Torque peaks during the engagement of the Harpoon-shift with the spring of $1.25 \mathrm{~mm}$ wire, (c) Torque peaks during the engagement of the Harpoon-shift with the spring of $1.4 \mathrm{~mm}$ wire. (d) Torque peaks during the engagement 
of the Harpoon-shift with the spring of $1.6 \mathrm{~mm}$ wire. Star indicates failed engagement, circle indicates successful engagement.

Fig. 25 (b) presents the peak values of the output torque at the input shaft of the prototype with the springs of $1.25 \mathrm{~mm}$ wire in the test rig, again engagements are performed through a range of differential speeds. The results demonstrate a similar trend to those shown in Fig. 25 (b), with a higher minimum speed required to move the guide ring to the engagement position, the minimum engagement speed is now $160 \mathrm{rpm}$, and the trend of increasing torque with increasing speed repeats itself. It is found that the peak torques in Fig. 25 (b) are lower for comparable speeds than in Fig. 25 (a). Fig. 25 (c) presents the peak values of the torque outputted at the input shaft of the prototype with the springs of $1.4 \mathrm{~mm}$ wire in the test rig with the same set of differential speeds. In this case the minimum speed is $340 \mathrm{rpm}$ before successful engagement occurs. This maintains the trend where stiffer springs require higher minimum speed to complete engagement. However, the peak engagement torque is more consistent with Fig. 25 (a) than it is with Fig. 25 (b), indicating that there is an optimal spring stiffness for the given configuration. Fig. 25 (d) presents the peak values of the output torque at the input shaft of the prototype with the springs of $1.6 \mathrm{~mm}$ wire in the test rig under the different speed differences. Results shown in the Fig. 25 (d) demonstrate that there is not satisfied engagement at any of the available differential speed.

\subsection{Discussion of Harpoon-shift in real application}

In the experimental results shown in Fig. 23 and 24, the speed differences are $120 \mathrm{rpm}, 300 \mathrm{rpm}$, and 500 rpm, respectively. Thus the angular velocity of the motor 1 speed and the dog gear increase significantly within a short time. However, in real application, the threshold of speed difference for Harpoon-shift to complete engagement will be significantly reduced, which is from $10 \mathrm{rpm}$ to $50 \mathrm{rpm}$ (see Section 4.2). In addition, the rotating inertia of the driving motor used in electric vehicles is much smaller than that of the internal combustion engine (ICE). Thus the shifting jerk of EVs equipped with Harpoon-Shift will be reduced significantly.

In order to further reduce shifting jerk in real applications of Harpoon-shift, the following methods would be helpful:

1) Torque spring stiffness will be optimized to eliminate the speed difference when the Harpoon-shift is locked-up, which helps to reduce the shifting shock during engagement. Particularly, for the multi-speed electric vehicles, torque spring stiffness for each gear should be adjusted respectively according to the equivalent rotating inertia of the powertrain upstream of the target gear since each gear ratio is different.

2) The threshold of speed difference for Harpoon-shift to finish engagement should be selected carefully. Larger speed discrepancy will result in larger shifting shock, while lower speed discrepancy will reduce the shifting shock, but this increases the engagement duration. Therefore, it is important to find the right compromise between the engaging duration and shifting shock.

3) Compared to ICEs, the driving motor is more controllable due to its much smaller inertia. Thus, it can be controlled actively during engagement to decline the shifting shock. 


\section{Conclusions}

A novel synchronizer, namely Harpoon-shift, for electric vehicles is presented and a mathematical model of the synchronization mechanism is developed in this paper. The transients of the Harpoon-shift mechanism during engagement is simulated and verified by the experiment using a full-scale Harpoonshift test rig. This demonstrates that the dynamic model is capable of capturing the transient characteristics of Harpoon-shift in the engaging phase. The dynamic model is then applied to explore the impact of the rotating inertia, speed and speed difference on the torsional vibration during engagement. Based on the simulation results, a conclusion can be drawn that both the rotating inertia and speed difference play a significant role on the transient responses of the Harpoon shift system, while rotating speed has almost no influence on the torsional vibration of the system.

Results achieved from simulation and experiment demonstrate that the applied mathematical model in this paper can be utilized to quantitatively study the impact of Harpoon-shift design parameters on the dynamic performance during engaging process. Furthermore, by integrating the Harpoon-shift model into a powertrain model, the gear shift transients of electric vehicles with Harpoon-shift can be studied thoroughly, and control strategies to improve the shifting quality can be designed and validated based on the integrated model.

Additional benefits of the proposed system have not yet been considered in detail in this paper, for example the energy consumption during actuation. As only a small force is required to engage and release the actuator, the energy consumed in this process does not have significant impacts on overall energy consuming. The pneumatic actuator applied in these tests with $600 \mathrm{KPa}$ pressure (47 N force) can produce $20 \mathrm{~mm}$ movement in $0.2 \mathrm{~s}$. It equates to an average power usage of 5 Watts which is very reasonable for completing gear engagement. The more important is that the actuation force and energy does not vary with speed or target gear.

\section{Acknowledgements}

The financial support for this work from Australian Research Council (Project Number DE170100134) is gratefully acknowledged. Scholarship from the University of Technology, Sydney, and the China Scholarship Council (CSC) for the first author is highly appreciated.

\section{Appendix A}

$F_{L t 1}$ in Eq. 9 and $F_{L t 2}$ in Eq. 45 are not constant variables. They can be calculated by

$$
\begin{aligned}
& F_{L t 1}= \begin{cases}0 & \left(0 \leq x_{s}<0.005 \mathrm{~m}\right) \\
F_{a} & \left(x_{s} \geq 0.005 \mathrm{~m}\right)\end{cases} \\
& F_{L t 2}= \begin{cases}0 & \left(0 \leq x_{s}<0.018 \mathrm{~m}\right) \\
F_{a} & \left(x_{s} \geq 0.018 \mathrm{~m}\right)\end{cases}
\end{aligned}
$$


When the sleeve prong touches the front face of the guide ring and the groove bottom of dog gear, its axial movement is blocked, where $x_{s}=0.005 \mathrm{~m}$ and $x_{s}=0.018 \mathrm{~m}$, respectively.

In addition, $F_{a}^{\prime}$ in Eq. 18 and $F_{a}^{\prime \prime}$ in Eq. 39 are not constant variables, and they are given by

$$
\begin{aligned}
& F_{a}^{\prime}=F_{a}-m_{s}\left(\ddot{\theta}_{s}-\ddot{\theta}_{r}\right) R_{\text {out }} \cot \beta_{1} \\
& F_{a}^{\prime \prime}=F_{a}-m_{s}\left(\ddot{\theta}_{s}-\ddot{\theta}_{g}\right) R_{\text {out }} \cot \beta_{2}
\end{aligned}
$$

\section{Appendix B}

The detailed friction calculation (Eq. 13) between the sleeve and the guide ring during the entire sliding phase is shown as follows:
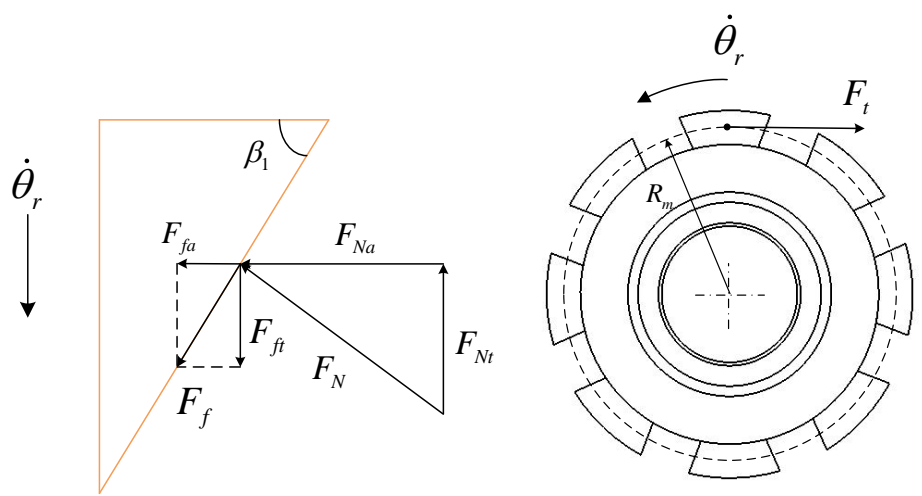

Fig. 26. The forces acting on the chamfer surface of guide ring.

$$
\begin{aligned}
& F_{N a}+F_{f a}=F_{a} \\
& F_{N a}=F_{N} \sin \beta_{1} \\
& F_{f a}=F_{f} \cos \beta_{1}=\mu_{s} F_{N} \cos \beta_{1} \\
& F_{N} \sin \beta_{1}+\mu_{s} F_{N} \cos \beta_{1}=F_{a} \\
& F_{N}=\frac{F_{a}}{\sin \beta_{1}+\mu_{s} \cos \beta_{1}}
\end{aligned}
$$

where $F_{N}$ is the normal force on the chamfer surface, $F_{f}$ is the friction force.

Explanations for equations: equation (57) is determined by substituting equation (55) and (56) into (54). Equation (58) is determined by (57).

Thus, the tangential force component $F_{t}$ acting on the guide ring can be expressed as 


$$
\begin{aligned}
F_{t} & =F_{N t}-F_{f t} \\
& =F_{N} \cos \beta_{1}-F_{f} \sin \beta_{1} \\
& =F_{N}\left(\cos \beta_{1}-\mu_{s} \sin \beta_{1}\right) \\
& =F_{a} \frac{\cos \beta_{1}-\mu_{s} \sin \beta_{1}}{\sin \beta_{1}+\mu_{s} \cos \beta_{1}} \\
& =F_{a} \frac{1-\mu_{s} \tan \beta_{1}}{\tan \beta_{1}+\mu_{s}}
\end{aligned}
$$

The torque generated by the tangential force $F_{t}$ can be calculated by

$$
T=-F_{t} R_{m}=-F_{a} R_{m} \frac{1-\mu_{s} \tan \beta_{1}}{\tan \beta_{1}+\mu_{s}}
$$

\begin{tabular}{|c|c|c|c|}
\hline Symbol & Unit & Value & Name \\
\hline$E_{S}$ & $\mathrm{~J}$ & General term & Spring energy \\
\hline$E_{K}$ & $\mathrm{~J}$ & General term & Kinetic energy \\
\hline$K_{S}$ & $\mathrm{Nm} / \mathrm{rad}$ & General term & Spring stiffness \\
\hline$\theta$ & $\mathrm{rad}$ & General term & Angular rotation \\
\hline$J_{G}$ & $\mathrm{~kg} \mathrm{~m}^{2}$ & General term & Inertia of the powertrain upstream of target gear \\
\hline$\omega_{G}$ & $\mathrm{rad} / \mathrm{s}$ & General term & Rotational speed of target gear \\
\hline$\omega_{S}$ & $\mathrm{rad} / \mathrm{s}$ & General term & Rotational speed of its respective shaft \\
\hline$\theta^{\prime}, \theta_{1}, \theta_{2}, \theta_{3}, \theta_{3}^{\prime}, \theta_{4}$ & $\mathrm{rad} / \mathrm{s}$ & $*$ & $\begin{array}{l}\text { Angular parameters of Harpoon-shift determining } \\
\text { engagement stages }\end{array}$ \\
\hline$\theta_{s}, \theta_{g b}, \theta_{g}, \theta_{m_{1}}, \theta_{r}$ & $\mathrm{rad} / \mathrm{s}$ & Variables & $\begin{array}{l}\text { The angular displacement of sleeve, gearbox output shaft, } \\
\text { dog gear, motor } 1 \text { and guide ring }\end{array}$ \\
\hline$x_{s}$ & $\mathrm{~m}$ & Variable & Axial displacement of sleeve \\
\hline$x_{t}$ & $\mathrm{~m}$ & 0.005 & $\begin{array}{l}\text { Axial distance between the front face of guide ring and } \\
\text { neutral position of sleeve }\end{array}$ \\
\hline$\beta_{1}, \beta_{2}$ & $\circ$ & * & Chamfer angle of the guide block and the groove \\
\hline$F_{a}$ & $\mathrm{~N}$ & Variable & Axial force generated by the pneumatic cylinder \\
\hline$F_{S G}$ & $\mathrm{~N}$ & General term & Force between sleeve and guide ring \\
\hline$F_{S S}$ & $\mathrm{~N}$ & General term & Force between sleeve and synchro groove \\
\hline$T_{S G f r i c}$ & $\mathrm{Nm}$ & General term & Friction torque between sleeve and guide ring \\
\hline$T_{\text {SSfric }}$ & $\mathrm{Nm}$ & General term & Friction torque between sleeve and synchro groove \\
\hline$T_{\text {spring }}$ & $\mathrm{Nm}$ & General term & Torque transmitted by the torque springs \\
\hline
\end{tabular}

The friction calculation (Eq. 34) between the sleeve and the groove of dog gear during the entire sliding phase is similar to the derivation presented above.

\section{Appendix C}

\section{Table A}

Parameters of Harpoon-shift model 


\begin{tabular}{|c|c|c|c|}
\hline$T_{c o}$ & $\mathrm{Nm}$ & General term & $\begin{array}{l}\text { Torque due to collision between sleeve and synchro } \\
\text { groove }\end{array}$ \\
\hline$T_{m_{1}}, T_{m_{2}}$ & $\mathrm{Nm}$ & Variables & Output torque of motor 1 and motor 2 \\
\hline$i_{g}$ & - & 2.88 & Gearbox ratio \\
\hline$J_{s}^{\prime}$ & $\mathrm{kg} \mathrm{m}^{2}$ & 0.00619 & $\begin{array}{l}\text { Equivalent rotational inertia of the sleeve, hub, and } \\
\text { coupling }\end{array}$ \\
\hline$J_{e q}^{\prime}$ & $\mathrm{kg} \mathrm{m}^{2}$ & 1.33221 & Equivalent rotational inertia of gearbox and motor 2 \\
\hline$J_{g}^{\prime}$ & $\mathrm{kg} \mathrm{m}^{2}$ & 0.00322 & Equivalent rotational inertia of dog gear and coupling \\
\hline$J_{m_{1}}^{\prime}$ & $\mathrm{kg} \mathrm{m}^{2}$ & 0.00160 & Equivalent rotational inertias of the motor 1 and coupling \\
\hline$J_{r}$ & $\mathrm{~kg} \mathrm{~m}^{2}$ & 0.00031 & Rotational inertia of guide ring \\
\hline$m_{s}$ & $\mathrm{~kg}$ & 0.80541 & Mass of sleeve \\
\hline$J_{m_{1}}$ & $\mathrm{~kg} \mathrm{~m}^{2}$ & 0.001 & Rotational inertia of motor 1 \\
\hline$J_{m_{2}}$ & $\mathrm{~kg} \mathrm{~m}^{2}$ & 0.15372 & Rotational inertia of motor 2 \\
\hline$J_{g b}^{\prime}$ & $\mathrm{kg} \mathrm{m}^{2}$ & 0.05724 & Equivalent rotational inertia of gearbox on the output shaft \\
\hline$k_{1}, k_{2}$ & $\mathrm{Nm} / \mathrm{rad}$ & $*$ & Equivalent stiffness coefficients of coupling inserts \\
\hline$k_{r g}$ & $\mathrm{Nm} / \mathrm{rad}$ & Variable & $\begin{array}{l}\text { Equivalent stiffness coefficient of the torque springs, } \\
\text { related to } k_{s 1} \text {. }\end{array}$ \\
\hline$k_{s r}$ & $\mathrm{Nm} / \mathrm{rad}$ & 768.3 & $\begin{array}{l}\text { Equivalent stiffness coefficient of collision between } \\
\text { sleeve and guide ring, corresponding to } K \text {. }\end{array}$ \\
\hline$k_{s g}$ & $\mathrm{Nm} / \mathrm{rad}$ & 768.3 & $\begin{array}{l}\text { Equivalent stiffness coefficient of collision between } \\
\text { sleeve and synchro groove, corresponding to } K \text {. }\end{array}$ \\
\hline$k_{s 1}$ & $\mathrm{~N} / \mathrm{m}$ & Variable & $\begin{array}{l}\text { Linear stiffness coefficient of torque springs, as shown in } \\
\text { Table } 3 .\end{array}$ \\
\hline$V_{o}$ & $\mathrm{~m}^{3}$ & $1 \times 10^{-6}$ & The chamber minimum volume at $x_{s}=0$ \\
\hline$\rho_{\text {air }}$ & $\mathrm{kg} / \mathrm{m}^{2}$ & 1.225 & Air density \\
\hline$C_{d}$ & - & 0.61 & Discharge coefficient \\
\hline$\beta_{c}$ & $\mathrm{~Pa}$ & $1.01 \times 10^{5}$ & Bulk modulus of air \\
\hline$Q_{c}$ & $\mathrm{~m}^{3} / \mathrm{s}$ & Variable & Air flow \\
\hline$P_{i n}$ & $\mathrm{~Pa}$ & $0.6 \times 10^{6}$ & Supply pressure provided by an air pump \\
\hline$P_{c}$ & $\mathrm{~Pa}$ & Variable & Air pressure in the cylinder chamber \\
\hline$A_{c}$ & $\mathrm{~m}^{2}$ & $7.85 \times 10^{-5}$ & Sectional area of the cylinder piston \\
\hline$A_{o}$ & $\mathrm{~m}^{2}$ & $7.07 \times 10^{-6}$ & Orifice area \\
\hline$n_{s}$ & - & 2 & The number of torque springs \\
\hline$n$ & - & 2.2 & Nonlinear exponent factor \\
\hline$N$ & - & 8 & The number of sleeve prongs \\
\hline$c_{r g}$ & $\mathrm{Nm} \mathrm{s} / \mathrm{rad}$ & 0.001 & $\begin{array}{l}\text { Equivalent damping coefficient between guide ring and } \\
\text { synchro groove }\end{array}$ \\
\hline$c_{s r}$ & $\mathrm{Nm} \mathrm{s} / \mathrm{rad}$ & 0.15366 & $\begin{array}{l}\text { Equivalent damping coefficient of collision between } \\
\text { sleeve and guide ring, corresponding to } c_{\max } \text {. }\end{array}$ \\
\hline$c_{s g}$ & $\mathrm{Nm} \mathrm{s} / \mathrm{rad}$ & 0.05762 & $\begin{array}{l}\text { Equivalent damping coefficient of collision between } \\
\text { sleeve and synchro groove, corresponding to } c_{\max } \text {. }\end{array}$ \\
\hline$c_{1}, c_{2}$ & $\mathrm{Nm} \mathrm{s} / \mathrm{rad}$ & 0.4 & Equivalent damping coefficient of coupling inserts \\
\hline$c_{s}, c_{g}$ & $\mathrm{Nm} \mathrm{s} / \mathrm{rad}$ & 0.001 & Damping coefficients \\
\hline
\end{tabular}




\begin{tabular}{|c|c|c|c|}
\hline$c_{x}$ & $\mathrm{~N} \mathrm{~s} / \mathrm{m}$ & 85 & Viscous friction coefficient \\
\hline$F_{L t 1}, F_{L t 2}$ & $\mathrm{~N}$ & Variables & $\begin{array}{l}\text { Force acting on the sleeve prongs from limiting } \\
\text { mechanism }\end{array}$ \\
\hline$F_{a}^{\prime}, F_{a}^{\prime \prime}$ & $\mathrm{N}$ & Variables & $\begin{array}{l}\text { Axial component of the normal forces as the sleeve prong } \\
\text { contacts the chamfer of the guide ring and groove, } \\
\text { respectively }\end{array}$ \\
\hline$\mu_{s g}$ & - & 0.05 & Dynamic friction coefficient \\
\hline$\mu_{s}, \mu_{s}^{\prime}$ & - & 0.05 & Chamfer friction coefficient \\
\hline$R_{s}$ & $\mathrm{~m}$ & $*$ & Mean distribution radius of torsion springs \\
\hline$R_{m}$ & $\mathrm{~m}$ & $*$ & $\begin{array}{l}\text { Mean contact radius between the guide block and sleeve } \\
\text { prong }\end{array}$ \\
\hline$R_{\text {out }}$ & $\mathrm{m}$ & $*$ & Outside radius of the dog gear \\
\hline$K$ & $\mathrm{~N} / \mathrm{m}$ & General term & Generalized stiffness coefficient \\
\hline$q$ & $\mathrm{~m}$ & General term & Relative penetration depth \\
\hline$\dot{q}$ & $\mathrm{~m} / \mathrm{s}$ & General term & Relative normal contact speed \\
\hline$D$ & $\mathrm{~N} \mathrm{~s} / \mathrm{m}$ & General term & Damping coefficient \\
\hline$c_{\max }$ & $\mathrm{N} \mathrm{s} / \mathrm{m}$ & General term & The maximum damping coefficient \\
\hline
\end{tabular}

Note: '—'denotes that there is no unit. '*' denotes that the value is sensitive.

\section{References}

[1] F. Di Nicola, A. Sorniotti, T. Holdstock, F. Viotto, S. Bertolotto, Optimization of a multiple-speed transmission for downsizing the motor of a fully electric vehicle, SAE International Journal of Alternative Powertrains 1 (2012-01-0630) (2012) 134-143.

[2] C. Changenet, X. Oviedo-Marlot, P. Velex, Power loss predictions in geared transmissions using thermal networks-application to a six speed manual gearbox, Transactions of the ASME: Journal of Mechanical Design, 128 (3) (2005) 618-625.

[3] B. Paffoni, R. Progri, R. Gras, J. Blouet, The hydrodynamic phase of gearbox synchromesh operation: the influence of radial and circumferential grooves, in: Proceedings of the Institution of Mechanical Engineers, Part J: Journal of Engineering Tribology, 211 (2) (1997) 107-116.

[4] R.J. Socin, L.K. Walters, Manual Transmission Synchronizers, SAE Technical Paper, 1968.

[5] H. Son, Y.S. Yoon, S.J. Kim, C. Song, K.S. Kim, Economic hybrid transmission system using clutchless geared manual transmission, in: Proceedings of the 28th Electric Vehicle Symposium and Exhibition, 3-6 May, Goyang Korea, 2015.

[6] C.Y. Tseng, C.H. Yu, Advanced shifting control of synchronizer mechanisms for clutchless automatic manual transmission in an electric vehicle, Mech. Mach. Theory 84 (2015) 37-56.

[7] H. Liu, Y. Lei, Z. Li, J. Zhang, Y. Li, Gear-shift strategy for a clutchless automated manual transmission in battery electric vehicles, SAE Int. J. Commer. Vehicles 5 (1) (2012) 57-62.

[8] S.J. Kim and K.S. Kim, Feasibility assessment and design optimisation of a clutchless multimode parallel hybrid electric powertrain, IEEE/ASME Trans. Mech. 21 (2) (2016) 774-786.

[9] Y.B. Bang, M. Yoon, 3-Speed Transmission using dual motors and one-way clutches, IEEE/ASME Trans. Mech. 21 (1) (2016) 412-418.

[10] A. Sorniotti, T. Holdstock, M. Everitt, M. Fracchia, F. Viotto, C. Cavallino, S Bertolotto, A novel clutchless multiple-speed transmission for electric axles. Int. J Powertrains 2 (2-3) (2013) 103-131.

[11] K. Zhao, Y. Liu, X. Huang, R. Yang, J. Wei, Uninterrupted shift transmission and its shift characteristics, IEEE/ASME Trans. Mech. 19 (1) (2014) 374-383. 
[12] Z. Lei, D. Sun, Y. Liu, D. Qin, Y. Zhang, Y. Yang, L. Chen, Analysis and coordinated control of mode transition and shifting for a full hybrid electric vehicle based on dual clutch transmissions, Mech. Mach. Theory 114 (2017) 125-140.

[13] M.S.R. Mousavi, A. Pakniyat, T. Wang, B. Boulet, Seamless dual brake transmission for electric vehicles: Design, control and experiment, Mech. Mach. Theory 94 (2015) 96-118.

[14] P.D. Walker, B. Zhu, N. Zhang, Powertrain dynamics and control of a two speed dual clutch transmission for electric vehicles, Mech. Syst. Signal Process. 85 (2017) 1-15.

[15] J. Liang, H. Yang, J. Wu, N. Zhang, P.D. Walker, Shifting and power sharing control of a novel dual input clutchless transmission for electric vehicles, Mech. Syst. Signal Process. 104 (2018) 725-743.

[16] J. Liang, H. Yang, J. Wu, N. Zhang, P.D. Walker, "Power on Shifting in Dual Input Clutchless Power-Shifting Transmission for Electric Vehicles," Mech. Mach. Theory. 121 (2018) 487-501.

[17] X. Zhou, P. Walker, N. Zhang, B.Zhu, J. Ruan, Numerical and experimental investigation of drag torque in a two-speed dual clutch transmission, Mech. Mach. Theory 79 (2014) 46-63.

[18] P.D. Walker, S.A. Rahman, B. Zhu, N. Zhang, Modelling, simulations, and optimisation of electric vehicles for analysis of transmission ratio selection, Adv. Mech. Eng. 5 (2013) 1-13.

[19] S.T. Razzacki, Synchroniser design: a mathematical and dimensional treatise, SAE Technical Paper, 2004.

[20] L. Lovas, D. Play, J. Marialigeti, J. Rigal, Mechanical behaviour simulation for synchromesh mechanism improvements, in: Proceedings of the Institution of Mechanical Engineers, Part D: J. of Auto. Eng. 220 (7) (2006) 919-945.

[21] Y. Fang, N. Zhang, P.D. Walker. Harpoon-shift. A new conception to implement gearshift in transmission, in: Proceedings of the 7th TM Symposium China-ICE HEV and EV Transmissions and Drive, 23-24 April, Shanghai, China, 2015.

[22] M. Montanari, F. Ronchi, C. Rossi, A. Tilli, A. Tonielli, Control and performance evaluation of a clutch servo system with hydraulic actuation, Control Engineering Practice, 12 (11) (2004) 13691379.

[23] J. Horn, J. Bamberger, P. Michau, S. Pindl, Flatness-based clutch control for automated manual transmissions, Control Engineering Practice, 11 (12) (2003) 1353-1359.

[24] P. Flores, H.M. Lankarani, Contact force models for multibody dynamics, Springer International Publishing, 2016.

[25] X. An, S. Pan, Analysis of contact model in multi-body system dynamic simulation, Computer Simulation, 25 (10) (2008) 98-101. 